\title{
المسؤولية الدولية الجنائية \\ عن الجرائم الإرهابية
}

\section{International criminal Responsibility \\ for terrorist crimes}

الباحث ميثم شاكر عبد الكاظم

معهد العلمين للاراسات

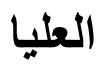

أ.د. - أدي نعيم المالكي

كلية القانون

جامعة بغداد 


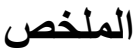

يتحمل الأفر اد المسؤولية الدولية الجنائية عن جر ائم دعم الإرهاب مهما كانت الصفة التي يتمتعون بها سواء كانو أشخاص عاديين أو رؤساء دول أو موظفي دولة، ويمكن مسألتهم من خلال القضاء الوطني أو القضاء الدولي. وبالر غم من عدم ذكر الجرائم الإرهابية في النظام الأساسي للمحكمة الجنائية الدولية، إلا أنه يمكن محاكمة الجماعات الإرهابية أمام المحكمة الجنائية الدولية عند ارتكابهم جرائم دولية ضمن الجر ائم الداخلة باختصاصها في نظامها الأساسي، كارتكابهر جر ائم الإبادة الجماعية أو جر ائم ضد الانسانية أو جر ائم حرب، ومحاكمة قادة ومسؤولي الدول الداعمة للإزرهاب تبعا لهم على أساس أحكام المساهمة الجنائية في ارتكاب جر ائم دولية تدخل في نطاق اختصاص الحكمة الجنائية

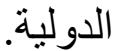
الكلمات المفتاحية: القانون الدولي، المسؤولية الدولية الجنائية، دعم الإرهاب.

\begin{abstract}
This research is entitled "International criminal Responsibility for terrorist crimes". Individuals bear the international criminal responsibility for supporting terrorist crimes, whatever their status, whether they are ordinary persons, heads of state or state officials. They could be prosecuting through national or international courts. Although terrorist crimes are not mentioned in the Statute of the International Criminal Court, terrorist groups may be prosecuting before the International Criminal Court when they commit international crimes within the jurisdiction under the Statute of this court, i.e., genocide, crimes against humanity or war crimes. Leaders and officials of States that support terrorism could be prosecuting also on the basis of the provisions of criminal contribution to the commission of international crimes within the jurisdiction of International Criminal Court.
\end{abstract}

Key Words: International Law, International Criminal Responsibility, Supporting terrorism. 


\section{المقدمة}

\section{Introduction}

أصبح الار هاب الثغل الثشاغل للثشعوب و الأمم على اختلاف مستو ياتها وخلال العشرين سنة

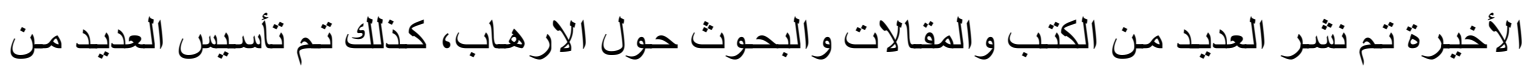

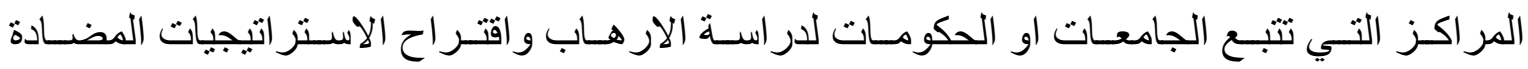

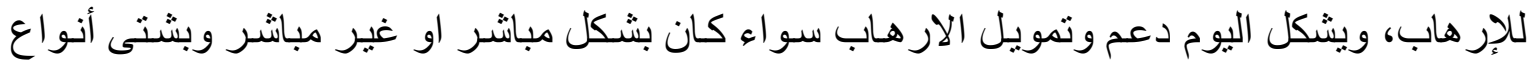

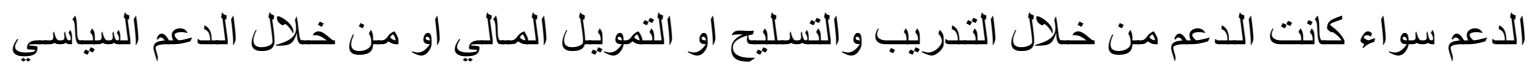

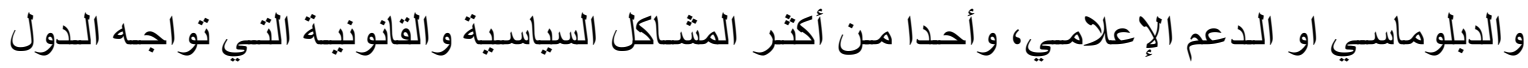
و النظام القانوني الدولي. تتجلى اهمية هذا البحث في محاولة معرفة مدى مسؤولية الدولة وقادة الدول معاً عند دعمهم الجر ائم الإرهابيـة والأساس القانوني لهذه المسؤولية وأي من الهحاكم الدولية التي يمكن اقامة هذه المسؤولية أمامها.

إن الفقه الدولي لم يكن متفقاً على اشخاص القانون الدولي العام ومكانة الفرد منه ابتداءً ومدى امكانية تحمل الأفر اد المسؤولية الدولية إلا مـا استقر عليه الفقه الدولي وهو إن الفرد أحد أنشخاص القانون الدولي وبالتالي فأنه يتحمل المسؤولية الدولية. وتعرف المسؤولية الدولية الجنائية الفردية بأنها "هو النظام الذي يعاقب بمقتضاه الأفر اد عما ارتكبوه من أفعال جسيمة تمس الجماعة الدولية بأكملها"'، كما أن هناك أفعال تؤدي مباشرة إلى المسؤولية الدولية للأفر اد دون الحاجة إلى ربط الفرد بالدولة بالإشارة إلى ضرورة التمييز بين المسؤولية الدولية للادولة و الفرد(").

وقد أنشارت المادة (Y0) من النظام الاساسي للمحكمة الجنائية الدولية الى المسؤولية الجنائية الفردية

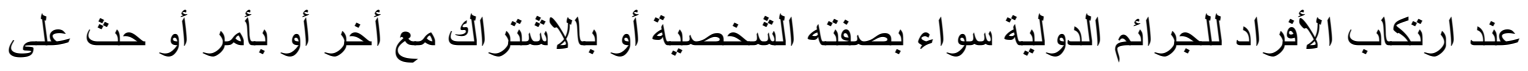

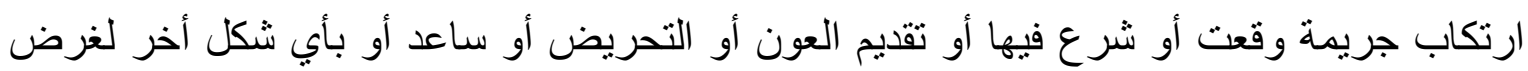

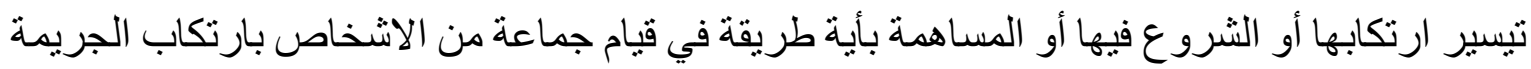

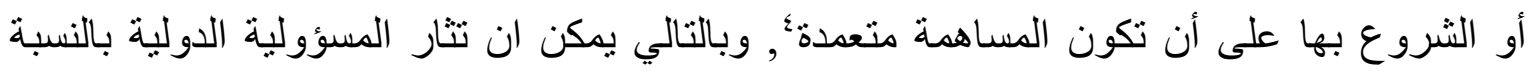
للفاعلين الاصلين الذين يشكلون مجمو عات إر هابية ترتكب جر ائم دولية.

كما ان النظام الأساسي للمحكمة الجنائية الدولية حرص على تقرير مسؤولية الرئيس عن أعمال

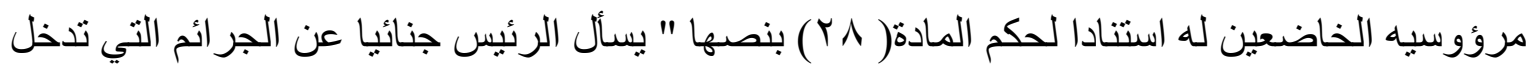


في اختصاص المحكمة", وبالتالي يمكن أن تثار المسؤولية الدولية الجنائية لقادة ومسؤولي الدول التي

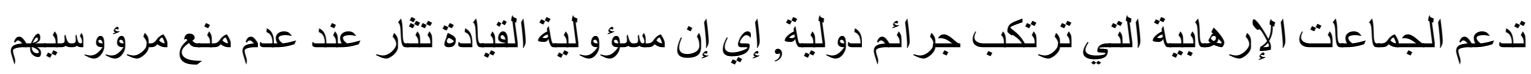
أو عدم معاقبتهم عند ارتكاب الجر ائم الدوليةه .

سوف سنتناول هذا البحث في مبحثين، نتناول في المبحث الأول المسؤولية الجنائية لمرتكبي الجرائم

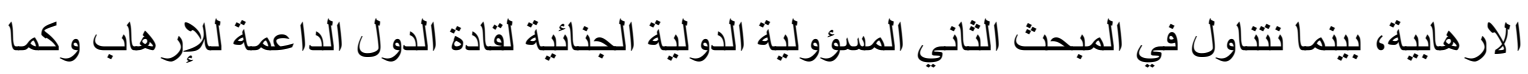
بلي:

المبحث الأول

المسؤولية الدولية الجنائية لمرتكبي الجرائم الإرهابية

International criminal Responsibility of The committer for terrorist crimes

لغرض الإحاطة بموضوع المسؤولية الجنائية لمرتكبي الجرائم الدولية سوف نتتاول هذا المبحث في

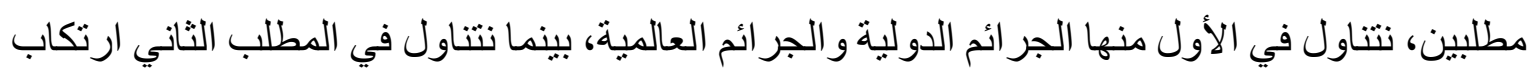
الجماعات الإر هابية جر ائم دولية، وكما يلي تباعاً:

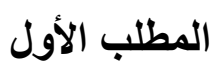

الجرائم الدولية والجرائم العالمية

\section{International Crimes and Universal Crimes}

سوف نتناول في هذا الفرع ثلاث فروع، نخصص الأول إلى التمييز بين الجرائم الدولية والجرائم

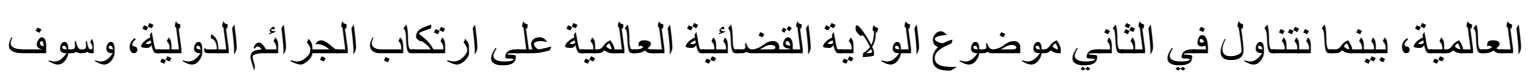

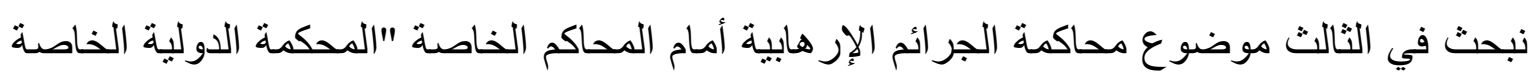

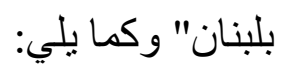

الفرع الأول: التمييز بين الجرائم الدولية والجرائم العالمية تختلف الجريمة العالمية عن الجريمة الدولية في عدة أمور منها " : 
( ) الجريمة العالمية ليست جريمة دولية، حتى وان ارتكبت على نطاق دولي، وان الجريمة العالمية جريمة عادية، وتختلف عن الجريمة الوطنية من حيث امكان ارتكابها في عدة دول، ومن هنا يبين لنا

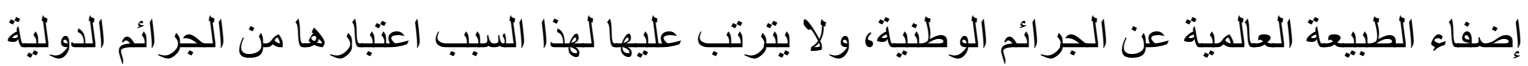
التي تدخل في نطاق القانون الدولي الجنائي.

(r) ان الجريمة العالمية ترتكب ضد مصلحة وطنية في الدول التي ترتكب فيها، وان كانت هذه المصلحة تهم الانسانية كلها، أما الجريمة الدولية فهي ترتكب ضد مصلحة لرندة دولية للمجتمع الدولي بأسره.

(T) الجريمة العالمية لا يتوفر فيها الركن الدولي باعتبار ها جريمة وطنية عادية، بينما يشترط قيام

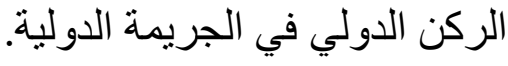

ويرتب على هذا الفارق أن الجريمة العالمية قد تنقلب الى جريمة دولية، اذا توفر لها الركن الدولي، وان لم تكن في أصلها ليس كذللك، فجريمة الإرهاب جريمة عالمية تعاقب عليها التشريعات الجنائية الوطنية، وتتعاون الدول جميعا من أجل القضاء عليه، و الذي ترتكبه أفر اد أو عصابات منظمة دون أن تكون لهم علاقة بدولة محددة، ولكن الإرهاب إذا مارسته دولة ضد دولة أخرى، أو ارتكبه أفر اد عاديون بتتجيع من دولة أخرى أو بدعم منها، فهنا تصبح المسألة ذات طابع دولي, وقد تثير المسؤولية الدولية

\section{الفرع الثاني: الولاية القضائية العالمية عن ارتكاب الجرائم الإرهابية}

ان الولاية القضائية العالمية أو ما يسمى بمبدأ الاختصاص العالمي وتعني الولاية القضائية التي

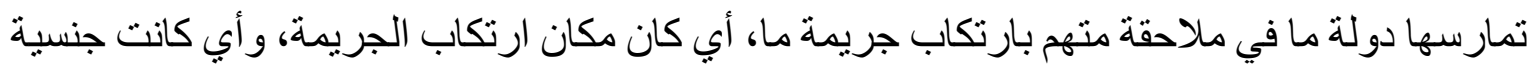
الفاعل أو جنسية الضحية، وان المعاهدات الدولية لمكافحة الإرهاب تشترطو وجود الثخص على اقليم الدولة حتى تمارس و لايتها القضائية .

وان العبرة في تحديد الاختصاص وفقا لمبدأ الاختصاص العالمي هو مكان القضض على المتهم دون اعتبار لمكان ارتكاب الجريمة أو جنسية المجنى عليه أو الفاعل، ويستمد هذا المبدأ أهميته من خطورة الاجر ام الدولي ولكثرة ارتكاب الجماعات الار هابية نشاطاتهم في اكثر من دولة، مما دعا الى قيام التنريعات الوطنية في توسيع اختصاصها القضائي وكذللك التعاون الدولي في تسليم مرتكبي الجرائم الار هابية لمحاكمتهم محاكمة عادل وضمان الملاحقة القضائية لمرتكبي الاعمال الارهابية". 
وسوف نطلع على بعض الوقائع الدولية التي تم اخضاع مرتكبي الاعمال الإرهابية للولاية القضائية للدولة ومنها:

\section{ا ـ قضية روزنربغ ضد لشكر- طيبة}

وتعتبر من القضايا التي نظرتها المحاكم الوطنية الارتكاب أعمال إرهابية، ومضمونها ان مجمو عة من الاعمال الارهابية التي طالت مدينة مومباي الهندية في جr نوفمبر ^ . . rا، والتي راح ضحيتها

$$
\text { اكثر من • } 17 \text { مدني من ضمنهم اجانب امريكيون وبريطانيون '. }
$$

وفي عام ب ا ـ r أقام الناجون اضافة الى اهالي الضحايا دعاوى في الولايات المتحدة الأمريكية أمام محكمة شرق ولاية نيويورك وعرفت بقضية روزنربغ ضد لشكر -طيبة، بالاستناد إلى قانون مكافحة الإرهاب، و على الرغم من ان الدعوى وجهت ضد هذا المجموعة الارهابية، إلا ان المدعون اقاموا ايضا دعوى ملحقة ضد افر اد جهاز المخابرات الباكستاني ومسؤولين سابقين اثنين كانوا في نفس الجهاز ، وكانت التهمة بأن المجمو عة الار هابية قد تلقت تدريبا وتجهيز ا واو امر من باكستان لتنفيذ هذه العملية، وقد ردت المحكمة الدعوى بحجة ان التهمة منسوبة لنخصيات تتمتع بالحصانة السياسية لدولة أجنبية هي باكستان، ومن خلال الطعن المقدم على قرار المحكمة فقد اصدرت في جلسة الاستئناف بأن لا يمكن استثناء ملاحقة انتهاكات القو اعد الأمرة وبالتالي فأن المتهمين خاضعين بحكم القانون إلى و لاية

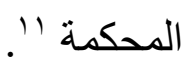

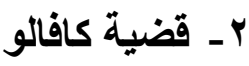

تتلخص قضية ريكاردو ميغل كافالو، وهو مو اطن أرجنتيني، عمل ضابط في البحرية الارجنتينية، بتوجيه سلسلة من الاتهامات الموجه اليه مفادها ارتكابه جر ائم ابادة و إرهاب وتعذيب ضد مواطنين أرجنتينين في أثناء حكم الدكتاتورية العسكرية أثناء الحرب القذرة ( 919 ( I I ) ).

وقد شرع القضاء الاسباني بالإجر اءات القضائية ضده امام محكمة في اسبانيا استنادا الى مبدأ الولاية القضائية العالمية، حيث سمح القانون القضائي الاسباني بملاحقة المتهمين بارتكاب جر ائم واقعة خارج اسبانيا بشرط ان تكون ضمن الجرائم الواردة في الاتفاقيات الدولية المصادق عليها من قبل إسبانيا وبالذات جر ائم الابادة وجر ائم الإر هاب ولم يحصر تطبيق القانون الاسباني على المو اطنين الاسبان بل

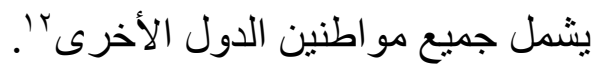


وكان كافالو يقيم في المكسيك متخذا اسم أخر، وقبض عليه في آب . . . . ، فطعن كافالو بطلب تسليمة الى اسبانيا امام المحاكم المكسيكية، وفي حزير ان ب . . ب و افقت المحكمة العليا في المكسيك على تسليمه بتهمتي ارتكاب جر ائم إبادة جماعية وإر هاب ولم تو افق المحكمة على طلب التسليم بتهمة التعذيب ، بحجة ان القضاء المكسيكي يطبق مبدأ التقادم على مرتكبي جر ائم التعذيب'. الفرع الثالث: محاكمة مرتكبي الجرائم الإرهابية أمام محاكم خاصة: المحكمة الدولية الخاصة بلبنان يتمتع مجلس الامن بصلاحيات واسعه تجاه حفظ السلم و الامن الدوليين و هذا ما نجده في تكوين المحاكم الدولية الخاصة لمحاكمة الجر ائم الإر هابية وكما فعله في انشاء المحكمة الدولية الخاصة بلبنان، و لا بد من التطرق الى كيفية انشاءها و هذا ما سوف نبحثه:

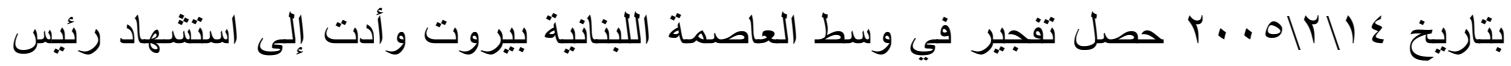
وزر اء لبنان الأسبق رفيق الحريري وأخرين، وعلى أثر ذلك أصدر مجلس الأمن الدولي قراره المرقم

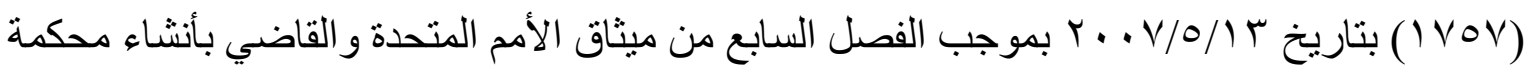
خاصة بلبنان ؛ وتعتبر هذه المحكمة اول محكمة دولية جزائية مؤقتة انشأت خصيصا للنظر في جريمة إرهابية وتطالب بمحاكمة مرتكبي الأعمال الإرهابية، كماوتعتبر آخر المحاكم الدولية التي أنشأها مجلس الامن الدولي بقر ار منه وفقا للفصل السابع من الميثاق 10. وقد رفع رئيس اللجنة التحقيقة القاضي (بيلمار) إلى الأمين العام للأمم المتحدة (كوفي أنان) بتاريخ

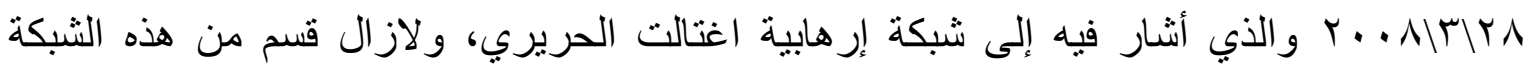
يو اصلون عمهم، وعلى أثر ذلك قدم الأمين العام تقريره إلى مجلس الأمن الدولي، ليكون الانتقال من عمل اللجنة التحقيقية إلى المحكمة اعتبار ا من ا كانون الثاني 9 ×. ب، و على أثر ذلك قامت المحكمة بعدة إجر اءات يمكن ايجاز ها بالنقاط التالية 17

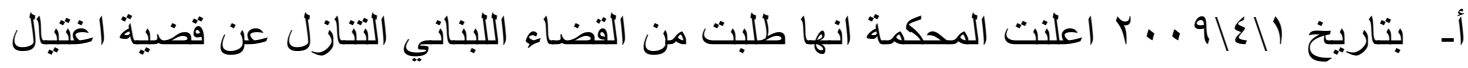

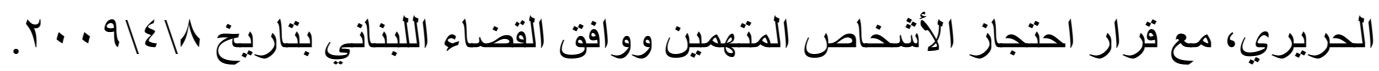

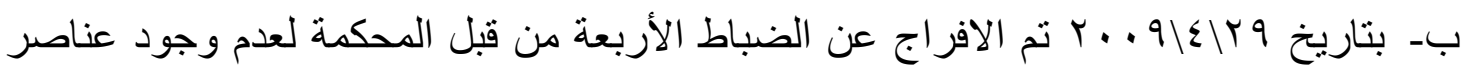

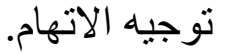




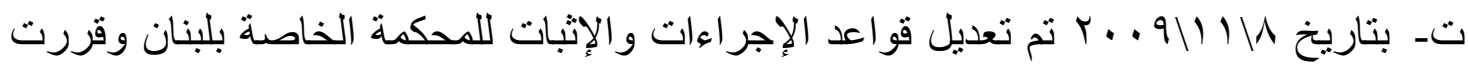
المحكمة محاكمة الثاهد الكاذب.

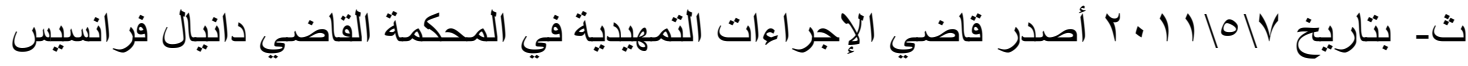
قرارا إعداديا لاحد الضباط (اللواء جميل السيد) بشأن تسليم ادلة شهود الزور الذي تسبب في الاعتقال التعسفي بحقه وثلاثة ضباط آخرين.

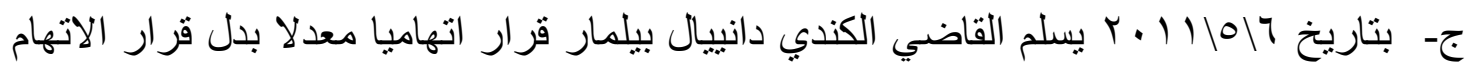

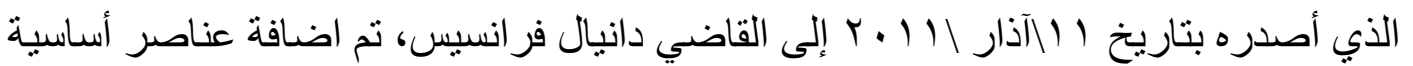
فيه لم تكن موجودة سابقا.

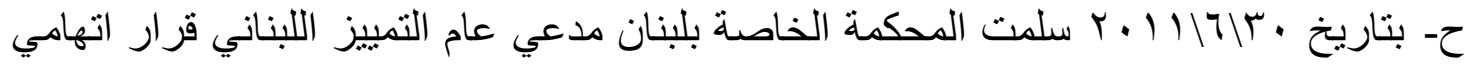
مع مذكر ات توقيف على ان ييقى هذا القرار سريا. و هنالك مجمو عة من الاجتهادات التي اصدرتها المحكمة الجنائية الدولية في لبنان، فقد ذهب غرفة الاستئناف في هذا المحكمة إلى ان وقوع نشاط إرهابي في زمن السلم، يمثل جريمة دولية بالاستناد إلى الى

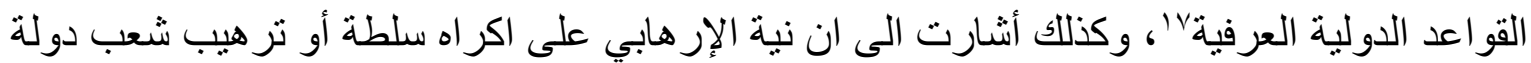

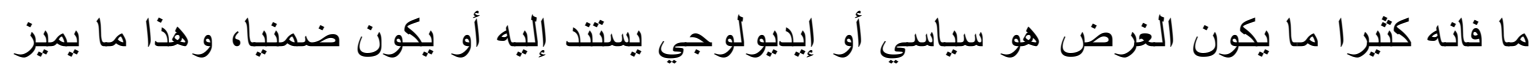

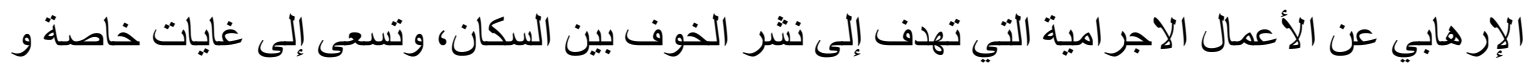

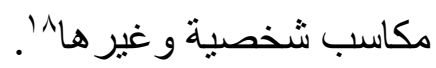
وإن المحكمة الدولية الخاصة بلبنان تعمل وفق نظامها الأساسي الذي تضمن اتجاهات ومبادئ حديثة في القضاء الدولي الجزائي، فقد جاء بمبادئ جديدة وخصوصا فيما ينعلق منها بالاختصاص للنظر بالجر ائم المحددة فيه، و على خلاف المحاكم الدولية الأخرى التي اقتصرت على اختصاصهاوفيق الجر ائم

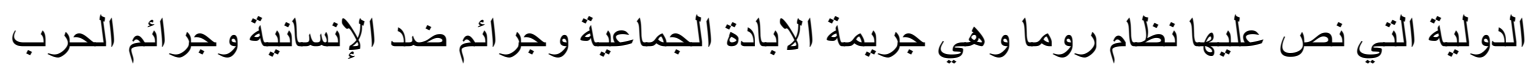

وجريمة العدوان 19.

وتجدر الاشارة ان المحكمة الخاصة بلبنان أشارت إلى إن المعاقبة على الإرهاب يلبي ضرورة

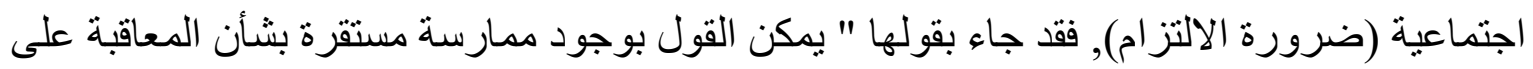

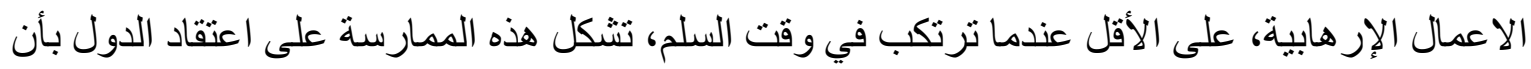
المعاقبة على الإرهاب تلبي ضرورة اجتماعية, ولذلك تصبح الز امية بوجود قاعدة ستوجبها "الاعتقاد 
كما ان النظام الاساسي للمحكمة لم يجيز للمدعي امام المحكمة المطالبة بحق التعويض امام نفش المحكمة وترك الحق للمتضرر في المطالبة به امام المحاكم الوطنية, وتقوم المحكمة بتزويد المتضرر

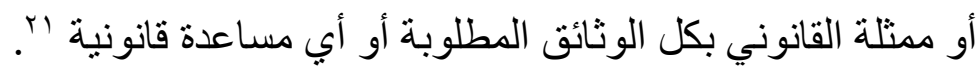

\author{
المطلب الثاني \\ ارتكاب الجماعات الإرهابية جرائم دولية
}

\title{
The Commission of International Crimes by Terrorist Groups
}

بداية يمكن طرح السؤال هنا هل يمكن أن يصنف الإرهاب في النزاعات المسلحة ضمن فئة جر ائم ابادة جماعية او جر ائم ضد الانسانية أو جر ائم حرب؟ هذا ما سوف نبحثه من خلال ما يلي:

يوجد هنالك اثكال قانوني لتجريم الاعمال الارهابية امام المحكمة الجنائية الدولية من خلال تحديد اختصاص المحكمة في المادة(0) من نظامها الاساسي للنظر في الجر ائم الدولية وهي ( ا - جريمة الابادة الجماعية Y- جر ائم ضد الانسانية ب- جرائم حرب عـ جريمة العدوان ) مما يعني عدم اختصاص المحكمة للنظر في جر ائم الارهاب، والسبب هو عدم ذكر تللك الجرائم في النظام الاساسي للمحكمة , حيث كان ضمن المقترحات المقدمة في مشروع نزام روما بان تختص المحكمة بجرائم الارهاب و الاتجار بالمخدر ات الى ان الاتجاه الغالب في المؤتمر التأسيسي للمحكة رفض ان تدرج هذه الجرائم ضمن اختصاص المحكمة، بسبب ان مؤتمر الامم المتحدة الدبلوماسي المعني بأنشاء المحكمة الجنائية الدولية ابدى اسفه لعدم الاتفاق على وضع تعريف مقبول لتلك الجريمتين مما تعذر ادراجهما ضمن الجر ائم الداخلة في اخصاص المحكمة بr.

بينما يتجه القاضي انطونيو كاسيزي و غيرهrّ، الى ان كل من القانون الدولي الانساني والقانون الدولي الجنائي في الوقت المعاصر يغطي الافعال الارهابية المرتكبة خلال نزاع مسلح دولي او داخلي، وكذلك فـأن القواعد الدولية تحظر الاعمال الارهابية في النزاعات المسلحة ,كما تحظر المادة(سب/I) من اتفاقية جنيف الرابعة لعام 9 \19 و التي اشارت الى حظر الاعمال الارهابية ضد المدنبين ,و على الرغم من ان الاصل في ذلك هو الارهاب المرتكب من قبل القوات المحتلة او الدول المحاربة، إلا ان هذه المادة اعلاه تضمنت قاعدة عامة تطبق في أي ظرف اذا تم اللجوء الى الار هاب من قبل الاطر اف 
المتحاربة، وبذلك فان الاعمال الارهابية التي ترتكبها جماعة منظمة على ارض اطر اف النزاع تعتبر محظورة دوليا.

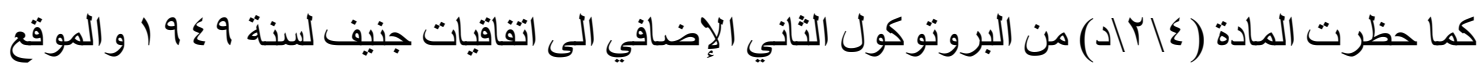
سنة 9VV ( ا، الاعمال الارهابية التي ترتكب ضد جميع الاشخاص الذين لا يثاركون في الاعمال القتالية، او كفوا عن الاشتر الك فيها، او التهديد بارتكاب تللك الاعمال گ؟ب

كما حظرت المادة (101) من البروتوكول الاول الاضافي لاتفاقيات الاربع لعام 9؛9 (، وكذلك المادة(T/ آT) من البروتوكول الاضافي الثاني على حظر اعمال العنف او التهديد به والرامية اساسا الى نشر الذعر بين السكان المدنيين ,كما تضمن ايضا القانون الدولي احكاما تحظر اعمالا قد تحظرها و احدة من المعاهدات المناهضة للإر هاب وان لم تستخدم مصطلح الارهاب، تبعا لنية وجنسية الفاعلين و الضحايا، فمثلا يمكن ان تطبق حظر بعض الاعمال الارهابية الواردة في المادة (ب) المشتركة في اتفاقيات جنيف الاربع في حالة ارتكاب اعمال عنف ضد اشخاص لا يشتركون مباثرة في الاعمال العدائية، كما يمكن ان تحظر الهجمات على المحطات النووية لتوليد الطاقة الكهربائية المذكورة في المادة (7ه) من البروتكول الاضافي الاول على بعض الاعمال المحظورة في الاتفاقية الدولية لقمع

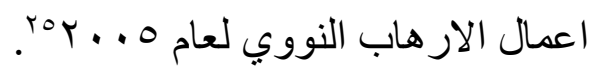

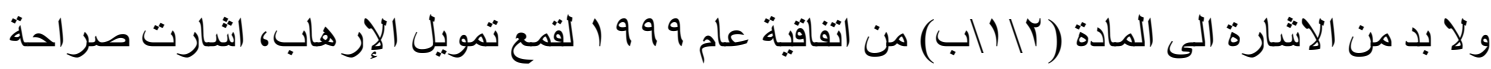
الى حالة نزاع مسلح"، أي ان الافعال الار هابية يمكن ان ترتكب خلال النزاع المسلح، وبما ان الاتفاقية صدقت عليها غالبية دول العالم مما يدل على تولد رأي عام دولي يؤيد تجريم الارهاب في فترة النزاع المسلح، وبالتالي يمكن اعتبار الارهاب جر ائم ابادة جماعية او جريمة ضد الانسانية أو جريمة حرب، و هذا ما نحاول ان نبحثثه من خلال ما يلي:

\section{الفرع الأول: جريمة الابادة الجماعية}

عرفت المادة السادسة من النظام الأساسي للمحكمة الجنائية الدولية جريمة الإبادة الجماعية بأنها " لغرض هذا النظام الأساسي تعني الإبادة الجماعية أي فعل من الأفعال التالية يرنكب بقصد إهلاك جماعة قومية أو أثنية أو عرقية أو دينية بصفتها هذه إهلاكا كليا او جزئيا:

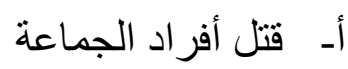
ب- إلحاق ضرر جسدي أو عقلي بأفر اد الجماعة 
ج- إخضاع الجماعة عمدا لأحو ال معيشية يقصد بها إهلاكها الفعلي كليا أو جزئيا. دـ فرض تدابير تستهدف منع الإنجاب داخل الجماعة

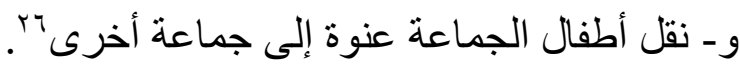

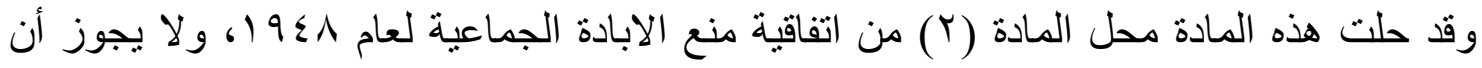

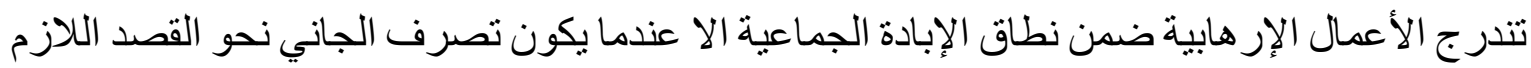

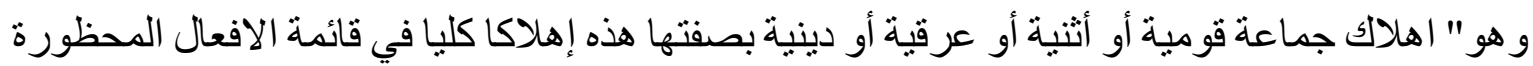

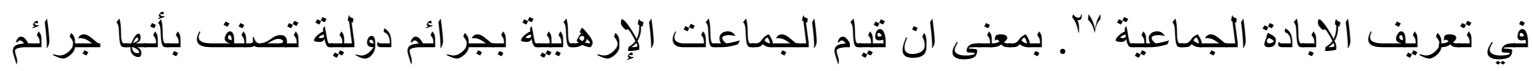
إبادة جماعية فأنها تسأل دوليا عن تلأل الأعمال الإجر امية.

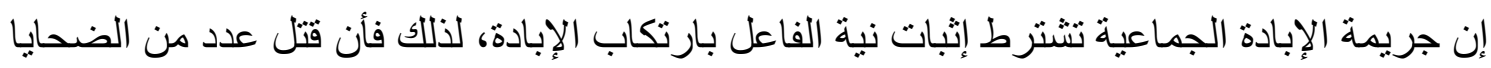

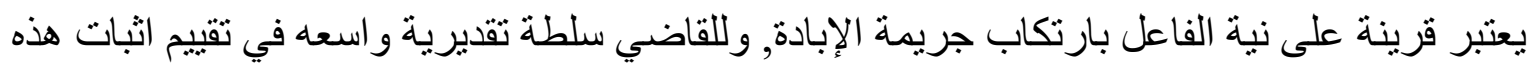

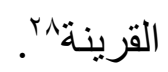
ومن الأمتلة على ارتكاب الجماعات الإرهابية جر ائم إبادة جماعية هو قيام تنظيم داعش الإرهابي

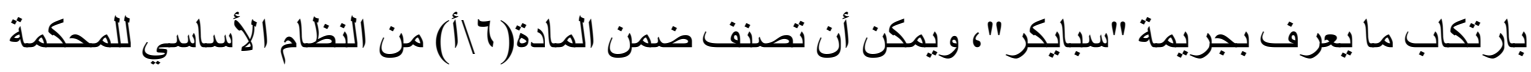

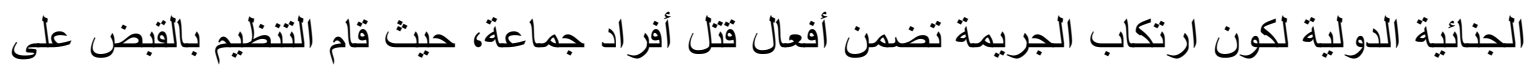

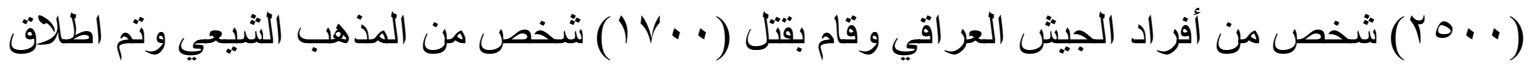

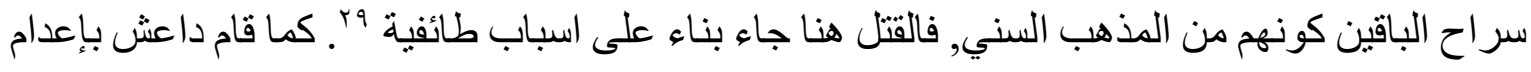
عدد كبير من أبناء عشيرة البو نمر في الرمادي غرب العراق، مما يمكن تصنيفها ضمن جر ائم الإبادة

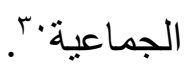

\section{الفرع الثاني: الإرهاب باعتباره جريمة ضد الانسانية}

عرفت المادة (IVV) من النظام الاساسي للمحكمة الجريمة ضد الانسانية بأنها أي فعل من الافعال

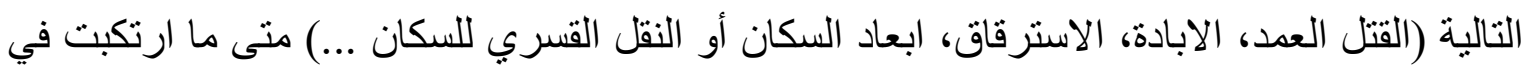

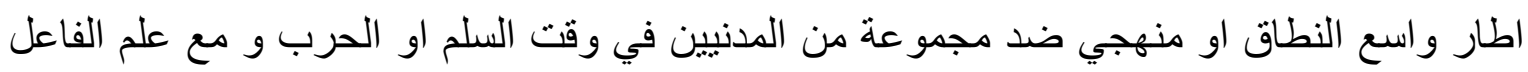

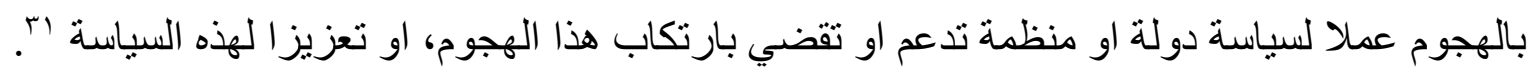
ويمكن ان تصل الافعال الارهابية الى مرتبة الجرائم ضد الانسانية ان توفرت العناصر التالية: 
أــ الفعل المادي المرتكب من قبل الجاني بغض النظر عن ما ارتكب في زمن السلم او الحرب، و لابد من ان يكون الفعل الارهابي جزء من هجوم واسع النطاق ومنهجي موجه ضد ضد السكان

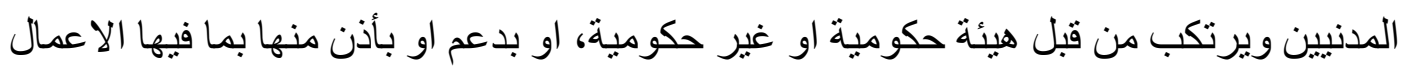

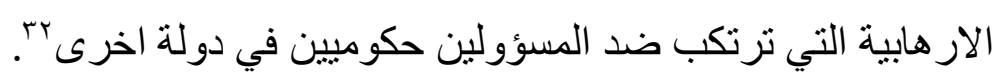

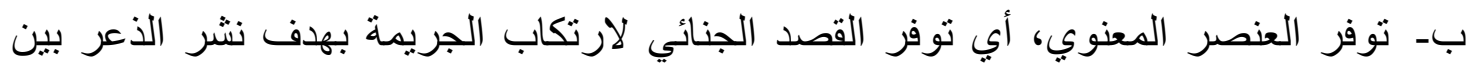

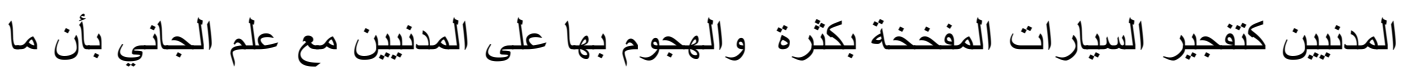
يقوم به هو جزء من اعتداء منظم واسع النطاق، ويمكن ان يكون الضحايا مدنيين او عسكريين

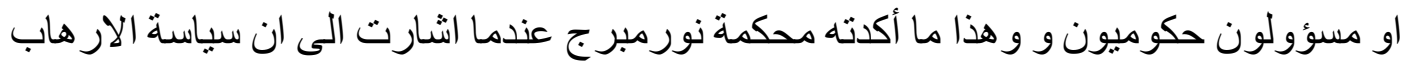

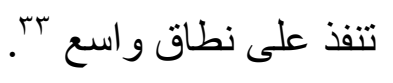

يعتبر الحكم الذي أصدرته المحكمة الدولية المؤقتة ليو غسلافيا السابقة والذي أدان سياسة الترهيب،

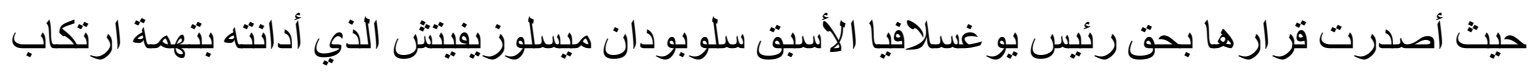

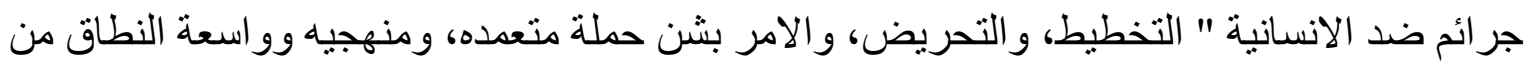
الإرهاب و العنف، والمساعدة والتثجيع على ارتكابها ضد الدننيين الالبان في كوسوفو...."، وكذللك قرارها ضد راديسلاف كريستفنش المتهم بالاضطهاد وسبب إرهاب المدنيين البوسنيين، في سربرينيتشا بقولها "تصف الغرفة المحاكمة الازمة الانسانية، وجر ائم الإرهاب و النقل القسري للنساء

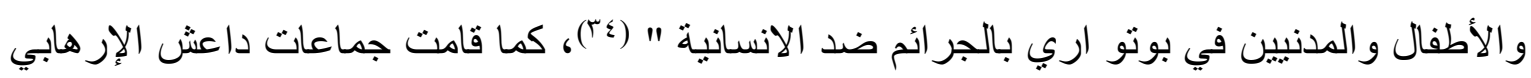
بخطف أكثر من ( ...0) شخص أكثر هم من النساء و الأطفال من الطائفة اليزيدية وارتكاب جر ائم قتل

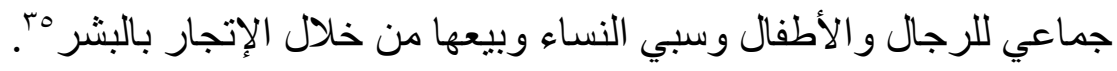

ومن الامثلة المقترحة هو قيام جماعة ارهابية في زمن السلم شن هجوم على المدنيين، وقاموا بالتورط بارتكاب اعمال وحثية ضد افر اد من الثرطة او الجيش و ومنها تفجير مر اكز الثرطة او تدمير مبنى

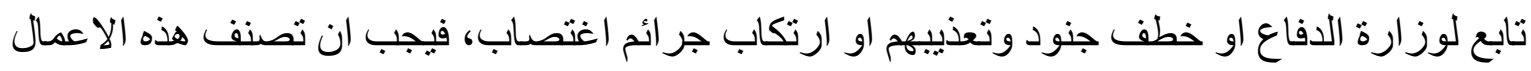
ضمن جرائم ضد الانسانية، وينضح مما ذكر ان توفر العناصر المادية يستوجب توفر القصد الخاص

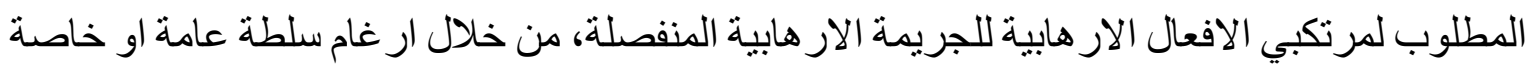

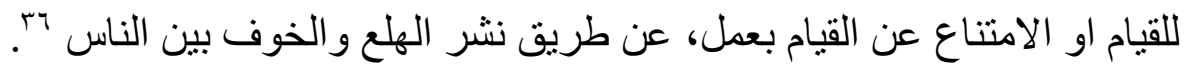




\section{الفرع الثالث: الارهاب باعتباره جريمة حرب}

يمكن الاعتر اض على العنو ان اعلاه باعتباره ان النظام الاساسي للمحكمة الجنائية الدولية وخصوصا المادة (^) عددت بشكل دقيق وموسع فئات الجرائم المختلفة التي تنطبق عليها وصف جريمة حرب و التي تدخل في اختصاص المحكمة (ICC) ولم يذكر الإر هاب من ضمنها، وان الجواب على ذلك هو بالرجوع للأحكام القانونية للنظام الأساسي للمحكمة فأنها لا تهدف الى تقنيين القواعد العرفية الدولية، حيث جاء في المادة (• () من النظام الأساسي للمحكمة "ليس في هذا الباب ما يفسر على انه يقيد او يمس بأي شكل من الاشكال قو اعد القانون الدولي القائمة او المتطورة ..."، بالإضافة الى القو اعد العرفية وقو اعد المعاهدات الدولية السابقة، لها احكام قانونية اخرى باعتبار ها اصبحت من القانون العرفي \ّام.

وفي السياق ذاته فان عناصر جريمة الحرب تتمحور في ارتكاب السلوك المحظور أو التهديد بتنفيذه وبعنف ضد المدنيين او الاشخاص الذين لا يشاركون في الاعمال العدائية بما فيهم العسكريين فانه يعتبر

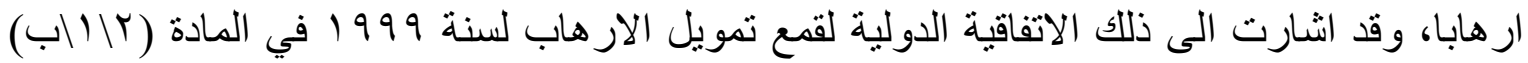
حيث حظرت التعرض للأشخاص غير المشاركين في الاعمال العدائية في حالة نشوب نزاع مسلح و اعتبرته فعلا ار هابيا ^ـ

اما العنصر المعنوي فقد بينته المادة (Y|Ol) من البرتوكول الاضافي الاول، والمادة (Y/Y) من البرتوكول الاضافي الثاني عندما اكدتا ان الافعال الارهابية تهدف الى نشر الذعر بين السكان و غيرهم في زمن النز اعات المسلحة، وكذلك فأن الاتفاقيات الدولية ذات الصلة بالإرهاب حرمت ذلك من الزام الدول الاطر اف لمو اجهة الار هاب سواء كان في زمن السلم او الحرب وقد اشارت الاتفاقية الدولية لقمع تمويل الار هاب في حالة قيام أي دولة اخرى في الاتفاقية على تمويل الافعال العنيفة ضد اشخاص لم يشاركو ا في الاعمال العدائية، بموجب هذه الاتفاقية يمكن المحاكمة بتهمة ارتكاب جر ائم حرب كل من قام بتمويل جر ائم ار هابية ارتكبت في الخارج و أي ان القانون الدولي الانساني والقانون الدولي الجنائي بغطيان افعال المحاربين الارهابية الخاضعة للحظر و التجريم 9ب.

وقد حصلت سابقة قضائية دولية حديثة عندما اعتبرت المحكمة الجنائية الدولية ليو غسلافيا السابقة في عام ץ +..r، ولأول مرة في القانون الدولي الجنائي عندما ادانت شخص عن مسؤوليته لارتكابه جريمة حرب ار هابية ضد المدنيين في سر اييفو، و اعتبرت المحكمة ان جريمة ارهاب السكان المدنيين تشكل عناصر مشتركة مع جرائم حرب اخرى، بالإضافة الى عناصر اخرى أكدتها الاتفاقية الدولية 
لقمع تمويل الارهاب، واستعملت المحكمة لفظ نثر الهلع بدل الارهاب للإشارة الى جريمة الحرب،

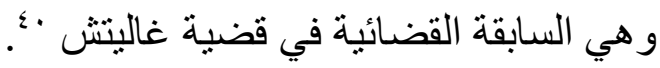

كما تضمن النظام الاساسي للمحكمة الجنائية الدولية لراوندا والمحكمة الخاصة بسير اليون أحكاما

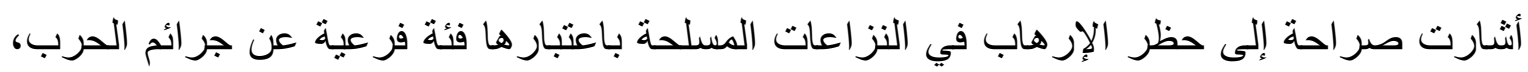

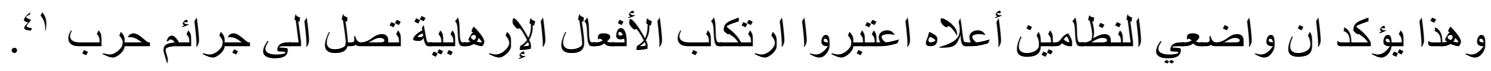

وان الجرائم الارهابية التي ارتكبها تتظيم داعش الارهابي في العراق وسوريا وغير ها من الدول

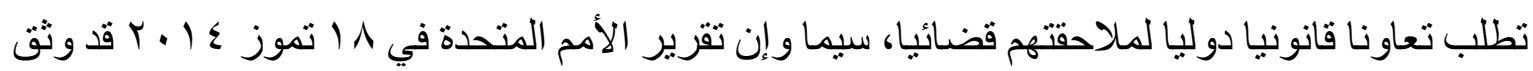
انتهاكات داعش و اشار الى امكانية ان ترقى الى جرائم حرب، ويمكن ان تمارس المحكمة الجنائية

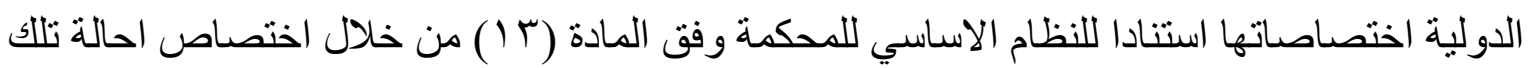

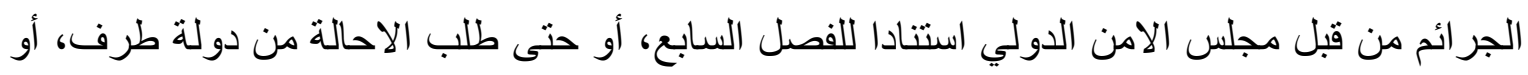

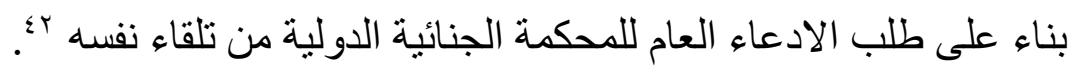
ويمكن ان يعاقب مرتكبي تللك الجر ائم من خلال ممارسة المحاكم الوطنبة اختصاصاتها استنادا الى

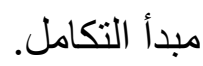

\author{
المبحث الثاني \\ المسؤولية الدولية الجنائية لقادة ومسؤولي الدول الداعمين للإرهاب
}

\title{
International criminal Responsibility for
}

\section{Leaders and officials of States supporting terrorism}

ان القانون الدولي العام يتميز عن غيره من فروع القانون العام، بسر عة تطوره لمواكبة المتغيرات الدولية، ولم يكن موضوع مسؤولية قادة ومسؤولي الدول الداعمين للإرهاب ببعيد عن هذه المتغيرات و لا سيما في مو اضيع اثيرت في الآونة الاخيرة لمفهوم حصانة قادة ومسؤولي الدول.

لذلك سوف نقسم هذا المبحث الى أربعة مطالب، نبحث في الأول منها أحكام المساهمة الجنائية، ونتناول

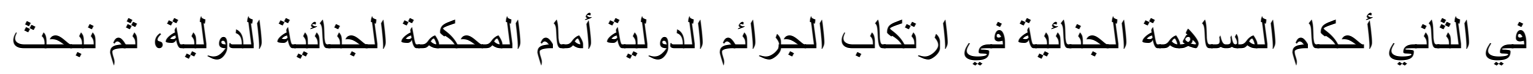


في المطلب الثالث عدم الاعتداد بالصفة الرسمية، واخير ا نبحث في المطلب الرابع مسؤولية القادة عن أعمال مرؤوسيهم، وهو ما سنتناوله تباعا:

المطلب الاول

\section{أحكام المساهمة الجنائية}

\section{Provisions of Criminal Contribution}

تعرف المساهمة اصطلاحا بأنها " السلوك الذي يؤدي الى تحقيق الفعل المكون للجريمة منى ماصدر عن أكثر من شخص يوجد بينهم رباط معنوي ولم يكن تعددهم ركنا في الجريمة التي وقعت" بـأ.

وتختلف اهمية كل دور من افعال الجناة المساهمين في ارتكاب الجريمة، لذلك يميز بين نو عين في المساهمة الجنائية: المساهمة الاصلية وتعني ان المساهم الاصلي هو الذي يقوم بدور رئيسي في تحقيق الجريمة؛ ؛، و المساهمة التبعية وتعني ان المساهم التبعي هو من يقوم بدور ثانوي في الجريمة من خلال

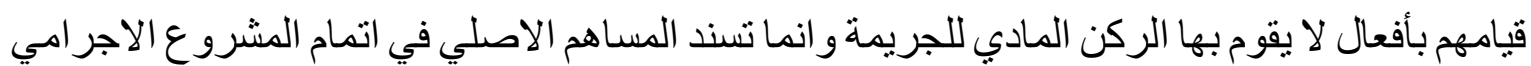
عن طريق التحريض أو الاتفاق أو المساعدة ؛؛

وقد وردت السساهمة الجنائية في بعض القو انين الجنائية الوطنية, فقد اشارت المادة ( • ) من قانون

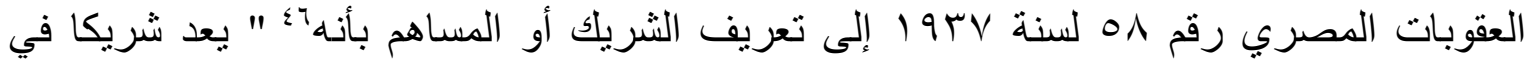
الجريمة: او لاـ كل من حرض على ارتكاب الفعل المكون للجريمة اذا كان هذا الفعل قد وقع بناء على لهى هذا التحريض. ثانيا- من اتفق مع غيره على ارتكاب الجريمة فوقعت بناءا على هذا الاتفاق. ثالثاـ من اعطى للفاعل أو الفاعلين سلاحا أو الالات أو أي شيء أخر مما استعمل في ارتكاب الجريمة مع علمه

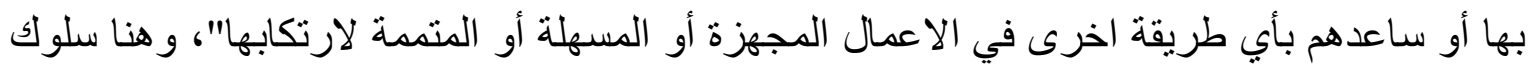

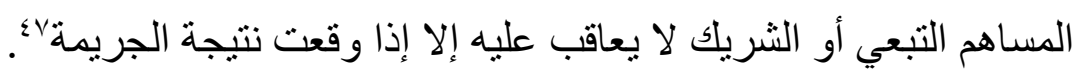

أما القانون العر اقي فقد أثشارت المادة (V \&) من قانون العقوبات على صور الركن المادي للمساهمة

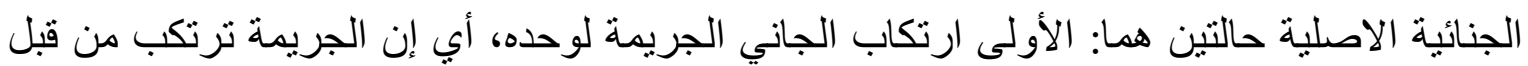
فاعل وحيد للركن المادي دون ان يساهم معه شخص اخر^^؛ و الثانية حالة ارتكاب الجاني الجريمة مع غيره أي أن يقوم الفاعلون في ارتكاب الاعمال التنفيذية معا ويساهموا بأفعالهم مجتمعه في النتيجةهُ؛؛ كمن يثارك اثثين او اكثر في نشاط جمع الأمو ال بغية القيام بتمويل منظمة إرهابية، كما اشارت المادة (T\\V) 
الفعل المكون للجريمة إذا كان هذا الشخص غير مسؤول جزائيا عنها لأي سبب"، كما نصت المادة

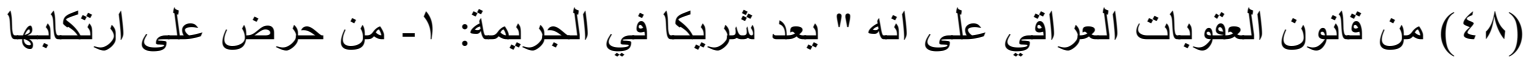
فوقعت بناءً على هذا التحريض. ؟ - من اتفق مع غيره على ارتكاب الجريمة فوقعت بناءً على هذا الاتفاق. r- من أعطى الفاعل سلاحا أو ألات أو أبي شيء أخر مما استعمل في ارتكاب الجريمة مع علمه أو ساعده بأي طريقة أخرى في الاعمال الممهدة أو المسهلة أو المتممة لارتكابها. هـ وجاءت مشابه للنص المصري.

وقد ورد الاشتر الك بالمساعدة في بعض القو انين الجنائية الداخلية باعتبار ها احدى صور المساهمة الاصلية أو المساهمة التبعية, فقد نصت المادة (9؟) من قانون العقوبات العر اقي على انه " يعد فاعلا للجريمة كل شريك كان حاضر ا أثناء ارتكابها أو ارتكاب أي فعل من الافعال المكون لها"، ونصت المادة (ך § ) من قانون العقوبات في دولة الامارات العربية المتحدة على انه "يعد في حكم الشريك المباشر كل شريك بالتسبب وجد في مكان الجريمة بقصد ارتكابها اذا لم يرتكبها غيره" اه.

ووسائل المساهمة التبعية نو عان معنوية ومادية, فالوسائل المعنوية هي التي ليس لها مظهر خارجي كالتحريض والاتفاق، أما الوسائل المادية فهي التي لها مظهر خارجي كالمساعدة مثنا من يقدم سلاحا للجاني أو يقدم سيارة مفخخة ليفجر ها، وإن الأعمال التي تدخل في المساهمة التبعية بوسائلها الثناث (التحريض والاتفاق و المساعدة) قد تكون سابقة للجريمة أو معاصرة لها أو مقارنة لها، أما الأعمال اللاحقة فلا تصلح لقيام الاشتر اك المعاقب علية قانونا، و انما قد يعاقب عليها كجريمة قائمة بذاتها كإعانة الجناة على الفرار من القضاء، أو اخفاء الأشياء المتحصلة من الجريمة؟ه

ويختلف الفقه والقضاء الدولي في تحديد المعيار للتمييز بين المساهم الاصلي و التبعي، وظهرت نظريتان هما: النظرية الأولى النظرية الثخصية وتعني إن من توافرت لدية نية الفاعل كان مساهما أصليا في ارتكاب الجريمة، وأما من توافرت لديه نية الثريك كان مساهما تبعيا في الجريمة، و النظرية الثانية هي النظرية الموضو عية وتعني إن المساهم الأصلي هو الذي يساهم في ارتكاب الاعمال التنفيذية للجريمة، أما المساهم التبعي فلا يأتي بعمل تنفيذي (مادي)، وانما تتمثل مساهمته في الأعمال السابقة لتنفيذ الجريمة، أي يساهم في الأعمال التحضيرية للجريمة، دون أن يكون له دور يذكر في ارتكاب ماديات الجريمة به

و الملاحظ إن النظرية الثانية النظرية الموضوعية هي الأقرب لتحديد المسؤولية الدولية عن دعم الإر هاب، لكونها أكثر دقة في رصد داعمي الإرهاب وضمان تقديمهم للعدالة و عدم إفلاتهم من العقاب، 
ومن جهة أخرى فإن النظرية الثخصية فيها تنخيص عام غير واضح يصعب التحقق منه لمعرفته

$$
\text { المساهمين في ارتكاب الجريمة. }
$$

ويثير موضوع المساهمة الجنائية في الجر ائم الدولية عدة امور نذكر منها:

أـ المساو اة بالكامل بين المساهمين في الجريمة الدولية على كافة مر احلها ابتداءً من الاعمال التحضيرية وانتهاء بمرحلة التنفيذ الكامل في ارتكاب الجريمة، ولا يوجد تفرقة بين الفاعل

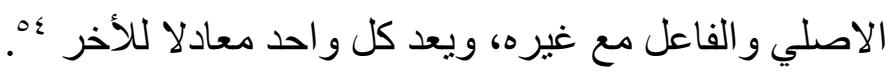

بـ مسؤولية الفاعل المعنوي ويعني الثخص الذي لا يباشر الاعمال التنفيذية للجريمة بنفسه و انما

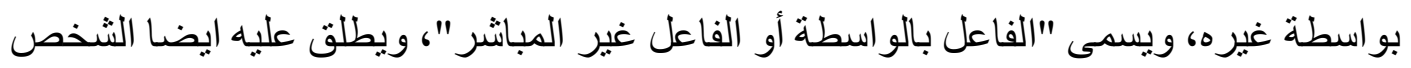
الذي يستعين بغيره لتنفيذ الجريمة، ويكون الغير هنا أداة للفاعل المعنوي لتحقيق عناصر

$$
\text { الجريمة.00. }
$$

ج- الاتفاق الجنائي: حيث يعتبر الاتفاق الجنائي صوره من المساهمة التبعية، وبالنظر لخطورته

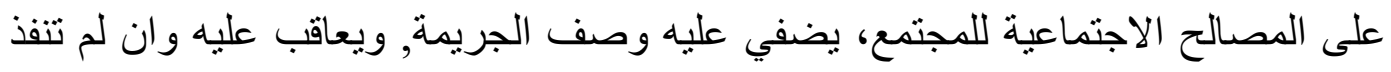
الجريمة التي تم الاتفاق على ارتكابها، وغالبا ما تكون في الجر ائم التي تفرض طبيعتها التفاهم على ارتكابها حيث ينعقد اتفاق بين عدة اشخاص، وتبدو واضحة في الجرائم الدولية التي تكون الدول طرفا فيها، كجر ائم دعم الار هاب، و ابادة الجنس البشري، ويمكن ان يتخذ الاتفاق الجنائي صورتين هما، الاولى هي المؤامرة ويقصد بها الاتفاق الذي يستهدف ارتكاب جر ائم محدده،

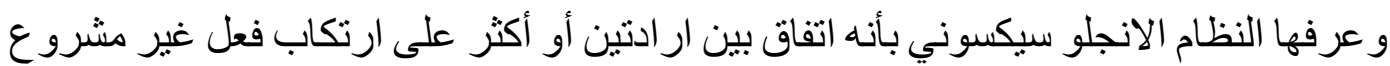

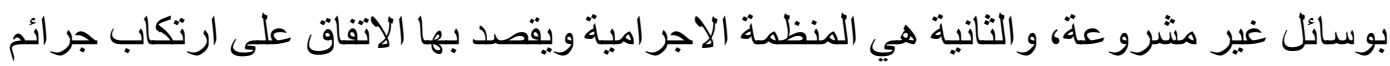
غير محددة $4{ }^{4}$ 
المطلب الثاني

أحكام المساهمة الجنائية أمام المحكمة الجنائية الدولية

\section{Provisions of Criminal Contribution before the International Criminal Court}

سوف نبحث في هذا المطلب موضوعين نبحث في الاول منها أنكال المساهمة الجنائية امام المحكمة

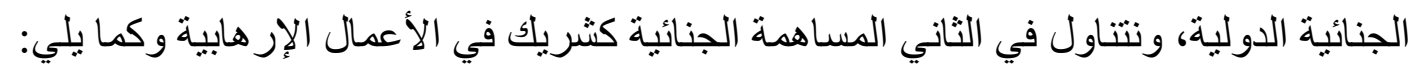

الفرع الأول: أشكال المساهمة الجنائية أمام المحكمة الجنائية الدولية

تناولت المادة (Yo) من النظام الاساسي للمحكمة الجنائية الدولية احكام المسؤولية الجنائية الفردية

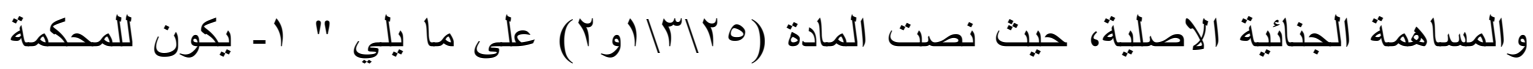

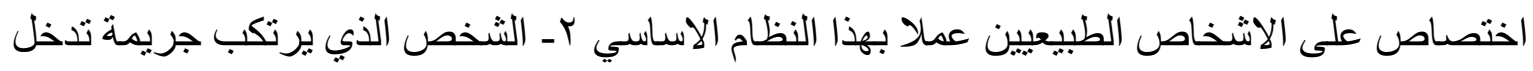

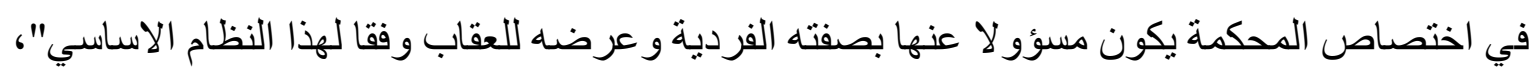

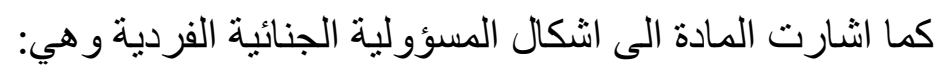

أولا: المساهمة الجنائية الاصلية

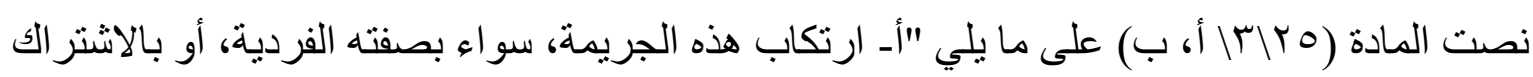

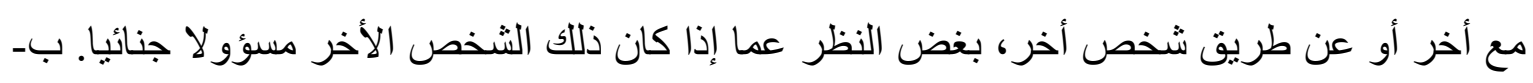
الامر أو الاغر اء بارتكاب، أو الحث على ارتكاب جريمة وقعت بالفعل أو شر ع فيها"، ويلاحظ الفقرتين

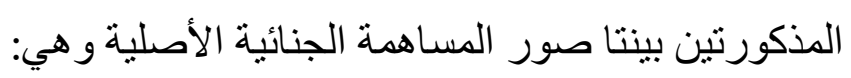

أــ الفاعل الذب يرتكب الجريمة وحدة, أب قيام فاعل الجريمة بارتكاب الركن المادي للجريمة

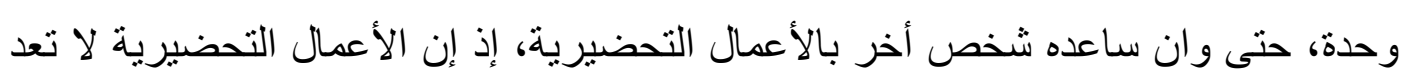

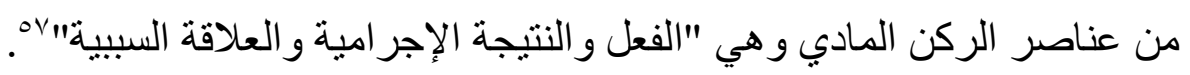

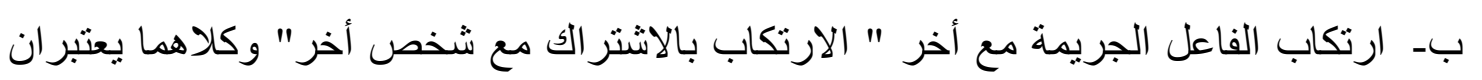

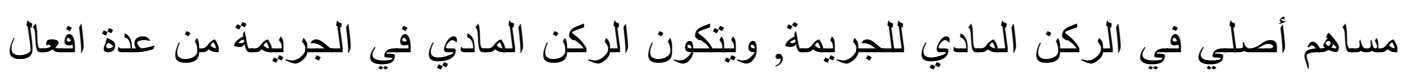

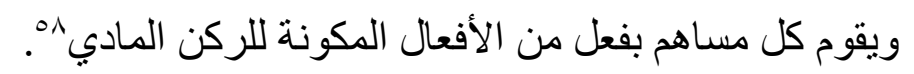

ج - المساهم الاصلي الذي يرتكب النشاط الاجر امي عن طريق شخص أخر أو ما يسمى "بالفاعل

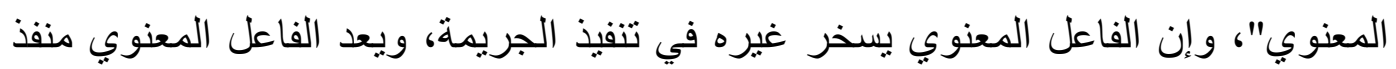


الجريمة عن طريق غيره، من خلال تحريض اخر على ارتكابها ويكون الأخير حسن نبة أو لايه مانع من مو انع المسؤوليةه9.

\section{ثانيا: المساهمة الجنائية التبعية}

نصت المادة (Y) باب، ج) على انه " بـ الأمر أو الاغر اء بارتكاب، أو الحث على ارتكاب جريمة وقعت بالفعل أو شرع فيها. ج- تقديم العون أو التحريض أو المساعدة بأب شكل أخر لغرض تيسير ارتكاب هذه الجريمة أو الثروع في ارتكابها بما في ذلك توفير وسائل ارتكابها"، ويلاحظ ان الفقرتين اعلاه بينتا اشكال المساهمة التبعية وهي:

أـ التحريض ويعني خلق فكرة لاى الجاني عن طريق أفعال أو أقوال ودفعه على ارتكابها، سواء تتحقق النتيجة أو تصل إلى الثروع في ارتكابها". بـ المساعدة وتكون من خلال تيسير ارتكاب الجريمة أو الثروع في ارتكابها عن طريق تقديم يد

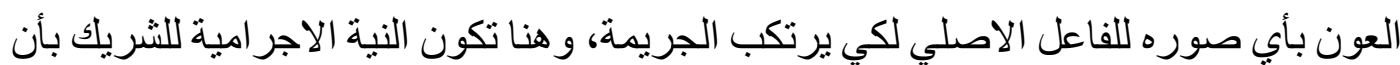
أعماله تساعد الفاعل على ارتكاب الجريمة". تـ الاتفاق ويعني انعقاد بين ار ادتين أو أكثر على ارتكاب الجريمة، ويفترض أن يقدم أحد الأطر اف عرض ويو افق عليه الأخر ، وهنا تكون إر ادة المتفقين منعادلة، ويشترط لقيام المساهمة الجنائية

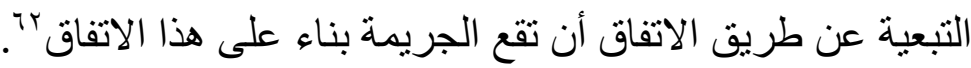
وإن اشكال المسؤولية الدولية الجنائية عن طريق المساعدة والتحريض (المؤازرة) على ارتكاب الجرائم الدولية تنطوي على قيام شخص (وهو الثريك في الجريمة ) بتقديم مساعدة فعلية (كتقديم أسلحة ومعدات وغير ها) إلى المرتكب الأساسي للجريمة، أو تثجيعه على ارتكابها أو تقديم الدعم المعنوي له، ويكون لهذه المساعدة أو التشجيع أو الدعم المعنوي الأثر الكبير لدفع الفاعل على ارتكاب الجريمة، وهنا

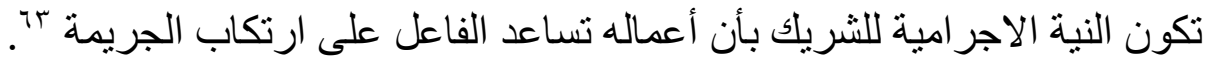

ثالثا: جريمة الاتفاق الجنائي (المشروع الاجرامي المشترك) نصت المادة (Y0/|د اد) على إنه " المساهمة بأية طريقة اخرى في قيام جماعة من الاشخاص، يعملون بقصد مشترك، بارتكاب هذه الجريمة أو الثروع في ارتكابها، على ان تكون هذه المساهمة متعدة وان 
1- إما بهدف تعزيز النشاط الإجرامي أو الغرض الإجرامي للجماعة، إذا كان هذا النشاط أو الغرض منطويا على ارتكاب جريمة تدخل في اختصاص الدحكمة.

$$
\text { r- أو مع العلم بنية ارتكاب الجريمة لدى هذه الجماعة. }
$$

وتتطلب جريمة الاتفاق الجنائي ضمن اختصاص المحكمة أن يكون مجمو عة من الأشخاص و ان يكون عددهم معقول، وقد تعاملت المحكمة الجنائية الدولية في قضية "سلوبودان ميلوسوفيتش" عن جرائم الابادة الجماعية وجر ائم ضد الانسانية وجر ائم الحرب في اقليم كوسوفو باعتباره شريكا في جريمة

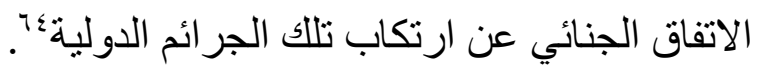

وقد تعامل القانون الدولي الجنائي في العصر الحديث مع الإجرام الجماعي من خلال نظريتين هما المشروع الإجر امي المشترك، و الارتكاب المشترك عن طريق السيطرة الكاملة على الجريمة، وفي كلتا النظريتين يعمل كل مشارك في الجريمة كفاعل أساسي أو أصلي. ويركز الششروع الإجر امي المشترك على النية المشتركة، ويتناول المسؤولية الجنائية للمشاركين في مخطط مشترك، ويتطلب القصد الجنائي المشترك (العنصر المعنوي) من خلال مساهمة المنهم بنشاطه في ارتكاب الجريمة، و هناك ثلاثة أنكال

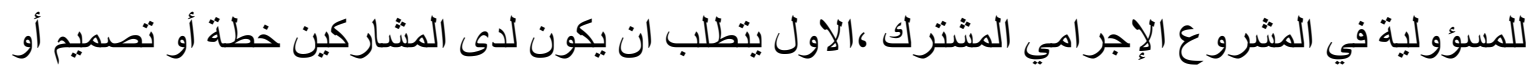
هدف مشترك ، وأن يكون لدى جميع المشاركين نفس القصد الجنائي الذي يدفعهم إلى ارتكاب الجريمة، و الثكل الثاني هو ترتيب المسؤولية الجنائية عن المشاركة في تصميم جنائي ينفذ ضمن إطار مؤسسي كما يحصل في معسكرات الاعتقال عن جرائم دولية، وتنشأ المسؤولية الجنائية إذا كانت المساهمة الجنائية للمشارك على قدر كبير من الأهمية، وتثمل إلى جانب القادة في المعسكر ومرتكبي الجريمة أولئك الذين يؤدون مهام إدارية (تسجيل السجناء الو افدين ) أو الكادر الطبي في المعتقل أو المعسكرهاب، كما حصل في التجاوزات إلى وجدتها اللجنة الطبية للصليب الأحمر الدولية والتي تعرض لها المحتجزين في سجن أبو غريب من قبل الكادر في السجن وتعاون الكادر الطبي في تخطبط وتنفيذ تحقيقات سريه

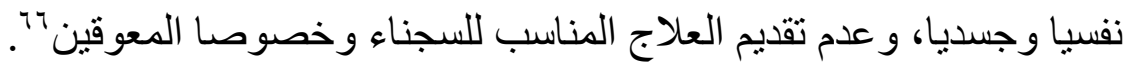

اما الثكل الثالث من اشكال المسؤولية الجنائية في المشروع الإجر امي المشترك فأن المسؤولية فيه تقوم عندما يرتكب واحد او اكثر جريمة اضافية لم يكن مخطط لها ولم تكن جزء من تصميم جنائي مشترك، مثال ذلك القيام بطرد مدنيين قسر ا من ار اضي محتلة، وقام احد المشاركين بقتل احد المدنيين خلال عملية طردهم، وقد اوضحت غرفت الاستئناف للمحكمة الجنائية الدولية ليو غسلافية السابقة في قضية كرديتش و الذي اكدت فيه ان المعيار الصحيح هو ادر الك احتمال وقوع امر ما، اما ادر الك امكانية 
وقوع مثل هذا الامر فليس مطلوب، كما واشارت غرفة الاستئناف للمحكمة الخاصة بلبنان الى انه ربما لم يكن للمجرم الثانوي النية لارتكاب جريمة اضافية، غير ان حدوث ارتكابها بات ممكنا من خلال الاستمرار في المشاركة في المشروع الاجر امي المشترك، بالرغم من تمكن المشارك توقع حدوث الجريمة الاضافية، كما بينت نفس المحكمة الى اختلاف درجات توجيه الادانة وبالتالي تخفيف العقوبات على المجرم الثانوي، واشارت كذلك الى أن المشروع الاجرامي المشترك يقوم على اعنبار ات تتعلق

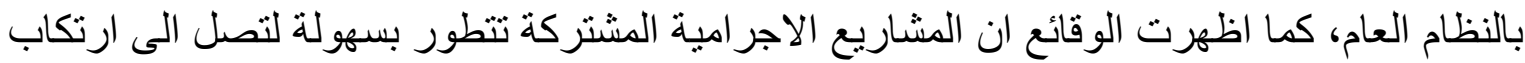
جرائم اكثر خطورة، كما يجب ان يتحمل المسؤولية الجنائية عن الضرر الذي ساعد وشجع على

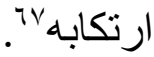

أما الارتكاب المشترك على العمل عن طريق السيطرة الكاملة على الجريمة فأنه يرتكز على العمل المشترك، وان تطبيقاتها نجدها في تفسير المادة (Y0/|أ) من النظام الاساسي للمحكمة الجنائية الدولية، حيث اشتارت الدائرة التمهيدية في قضية "لوبانغا" الى ان يعتبر العقل المدبر وهو الثخص الذي يسيطر على ارتكاب الجريمة، مرتكبا اساسيا للجريمة بالر غم من ابتعاده عن مسرح الجريمة، وان قرار عدم ارتكاب الجريمة او عدم ارتكابها وكيفية تنفيذها تقع بين يديه، وبذلك تعتبر ارتكاب الجريمة على اساس

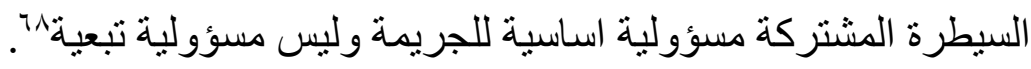

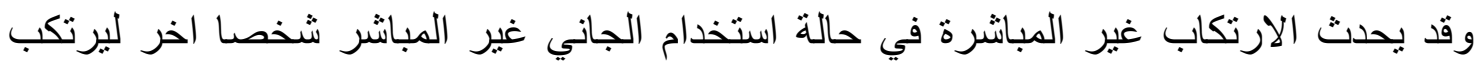

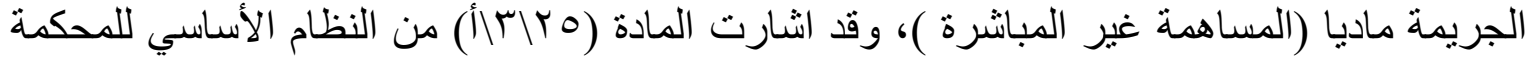
الجنائية الدولية الى شمول الارتكاب غير المبانر بغض النظر عن تحمل الجاني الذي يرتكب الجريمة ماديا المسؤولية الجنائية أم لا، حيث يقوم الجاني الأساسي باستخدام مرتكب الفعل المادي كأداة لارتكاب لإني الجريمة، ويعتبر اولئك الفئة من الجناة الذين يققون خلف مرتكب الجريمة هو ذالك المستمد من السيطرة على تتظيم هرمي، وقد أوضحت الدائرة التمهيدية في المحكمة الجنائية الدولية حتى يكون التنظيم قائم على بنيه هرمية تضم العدد الكافي من المرؤوسين الذين يمكن استبدالهم بما يضمن الامتثال لأرادت القائد، أي ان الجاني المسؤول عن أفعال الجاني مرتكب الجريمة لديه القدرة على تحقيق الهدف

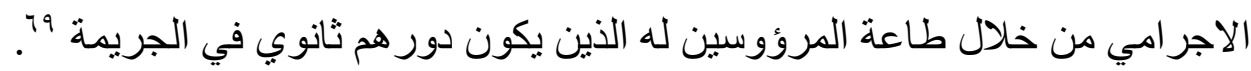
ومن أثنكال المسؤولية الدولية الجنائية الأخرى التخطيط لارتكاب جرائم دولية فأنه يشمل الاتفاق

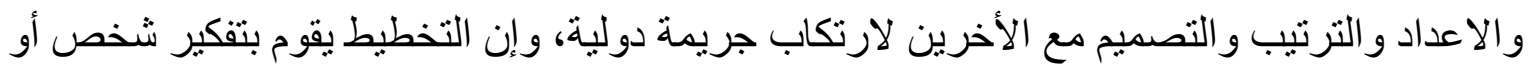
مجمو عة أشخاص بالتفكير في مخطط لارتكاب جريمة في مرحلتي التحضير و التنفيذ ل. 


\section{الفرع الثاني: المساهمة الجنائية كشريك في الأعمال الإرهابية}

ان الصكوك الدولية ذات الصلة بالإر هاب تقضي معاقبة الفاعلين المنفذين و الثركاء على حد سواء، سواء في الجرائم المرتكبة أو الثروع في ارتكابها , وكذلك منظمو الاعمال او الذين يهددون بها، وتختلف تفسير درجة المشاركة الجنائية في الاتفاقيات الدولية ذات الصلة بالإرهاب، فمثلا اتفاقية المو اد

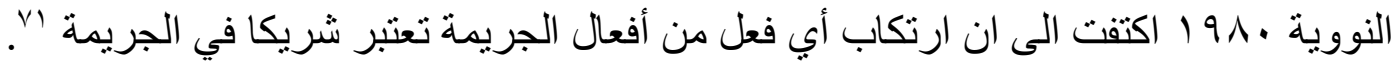

بينما أثنارت اتفاقية قمع تمويل الإر هاب لسنة 999 في المادة (Y|O) الى أن أي شخص يرتكب الجريمة أو عندما يساهم كثريك فيها أو ينظم ارتكابها أو يأمر أثخاص اخرين بارتكاب، كما أثنارت المادة (Y|0|ج) الى أن المشاركة في قيام مجموعة من الأشخاص لديهم قصد مشترك بارتكاب جريمة

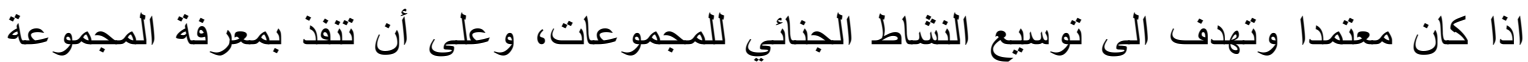
لارتكاب الجريمة، كما أثنارت الاتفاقية الى أن الركن المعنوي للجريمة وهو قصد أو علم مرتكب الجريمة أن تستخدم الاموال في ارتكاب جريمة إرهابية، وأوصت الاتفاقية أيضا الى تجريم الاعمال

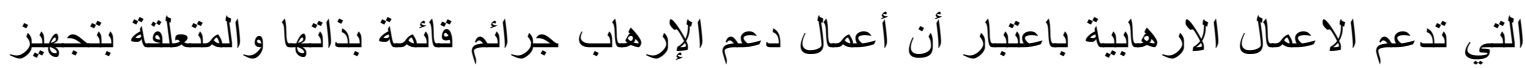

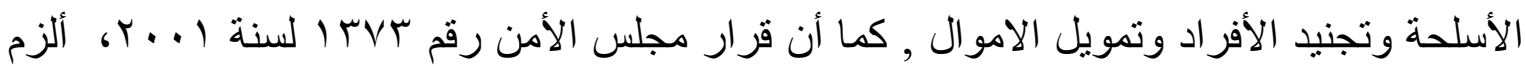
الدول على النص في تشريعاتها مكافحة الإرهاب وكذلك تجريم أي عمل يمثل مساندة أو تحضيرا

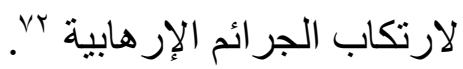

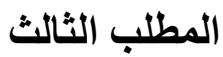

\section{عدم الاعتداد بالصفة الرسمية}

\section{Irrelevance of Official Capacity}

إن الحصانة القضائية التي منحها القانون الدولي لمصلحة رؤساء الدول و الوزر اء وممثلي دولهم أثناء ممارستهم وظائفهم، تثمل المحاكم المدنية بالإضافة الى المحاكم الجنائية وقد أثار بعض الدفكرين إلى الى

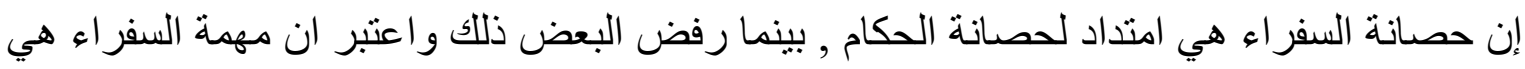
امتداد لحصانة الحكام، وان مهمة المسؤول السياسي هي تمثيل دولته لا تختلف عن التي يقوم بها الدبلوماسي، اما تقارب حصانة الحكام وحصانة الدول ففي العصور الوسطى كانت الدولة ورئيسها يشكلان كيان واحد، وكان الاعتقاد السائد إن حصانة الدولة متفر عة من حصانة رئيسها، ويرى البعض 
ان رئيس الدولة لله حصانه لنخصه و اسرته وحاثيتها، كما وان مفهوم الحصانة المتعلق بالسيادة انقسم الى قسمين عندما انفصلت الدولة عن رئيسها في العصور المتقدمة، وبما ان مصدر ها واحد فأن تطبيق القو اعد المتعلقة بحصانة الدول تطبق على حصانة الحكام (VT). ويثير احمد ابو الوفا الى انه "لا يخامر احد الثك في الحصانات والامتياز ات الدبلوماسية تتعارض على الاقل من حيث الظاهر ومسألة حقوق الانسان، ذلك ان الحصانة كما قلنا يترتب عليها عدم امكانية محاكمة من يتمتع بها جنائيا امام المحاكم الوطنية عن الجرائم التي يرتكبونها، فضلا عن عدم امكانية مطالبته مدنيا وفي احوال معينة بالحقوق المدنية الناجمة عن الفعل الذي ارتكبه (乏). وقد اسفر مؤتمر السلام عن عقد معاهدة فرساي 91919 بعد الحرب العالمية الاولى وتكمن اهية هذه المعاهدة باعتبار ها اول وثيقه دولية تعترف من الناحية القانونية بالمسؤولية الجنائية الثخصية لرئيس الدولة عن الافعال التي يرتكبها او يأمر بارتكابها عندما يكون في السلطة (vo). اما المحكمة الجنائية الدولية لم تعترف بالحصانة والامتياز ات المقررة للقائد ورؤساء الدول عند ارتكابهم جر ائم دولية، استنادا الى المادة (YV) من النظام الاساسي للمحكمة والتي نصت " ا ـ يطبق هذا النظام الاساسي على جميع الاشخاص بصورة متساوية دون أي تمييز بسبب الصفة الرسمية، وبوجه خاص فإن الصفة الرسمية للشخص، سو اء كان رئيسا لدولة أو حكومة أو عضو ا في حكومة أو برلمان أو ممثلا منتخبا أو موظفا حكوميا، لا تعفيه بأي حال من الاحوال من المسؤولية الجنائية بموجب هذا النظام الأساسي، كما أنها لا تشكل، في حد ذاتها، سبيا لتخفيف العقوبة. بـ لا تحول الحصانات أو القو اعد الإجر ائية الخاصة التي ترتبط بالصفة الرسمية للشخص، سواء كانت في إطار القانون الوطني أو الدولي، دون ممارسة المحكمة اختصاصاتها على هذا الثخص" (V7).

حيث جاءت المادة (YV) بموضوع مهم وهو عدم الاعتداد بالصفة الرسمية للأشخاص المتهمين بارتكاب جر ائم دولية، ضمن الجرائم الداخلة في اختصاص المحكمة ودون أي تمييز بالمنصب الذي يثغله الشخص المسؤول، ولا يتأثز الحكم الصادر من المحكمة لارتكاب أي فعل من الأفعال المعاقب عليها في النظام الأساسي للمحكمة فيما يتعلق بالإعفاء من المسؤولية أو التخفيف من العقوبة'ح'. وبعد تقرير هذا النص في النظام الاساسي للمحكة, فأنه لا يمكن التمسك بالصفة الرسمية لقادة ومسؤولي الدول، و ان تذرعهم بالصفة الرسمية لا يكون أي اثر قانوني يستفيد منه قادة الدول في الدفاع

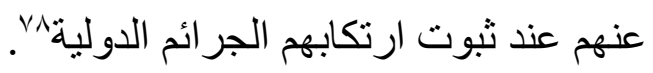


ويلاحظ إن النظام الأساسي أثناره في المادة أعلاه إلى إن الحصانات و الامتياز ات التي يرتبها القانون الدولي لبعض الاشخاص بالنظر لصفتهم الرسمية او الوظيفية، لا يمكن ان تعيق الدحكمة في مبانرة

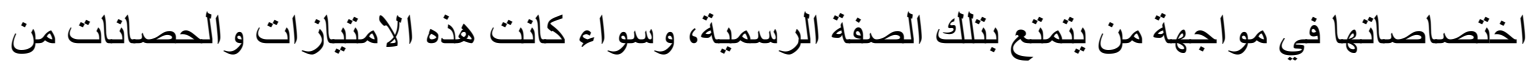

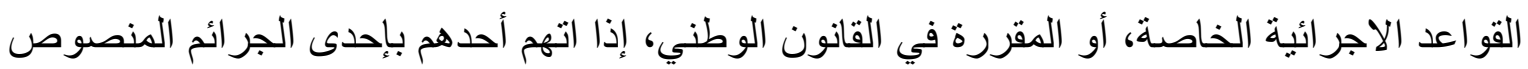
عليها في النظام الاساسي للمحكمة.

و لا بد من الاشارة إلى أن محكمة يو غسلافيا السابقة ب99 19 بينت في نظامها الاساسي بأن المسؤولية

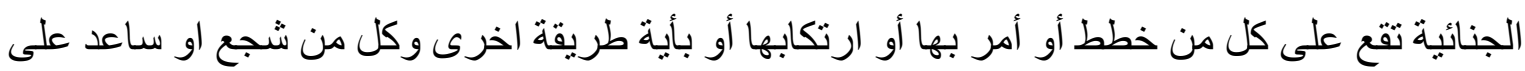

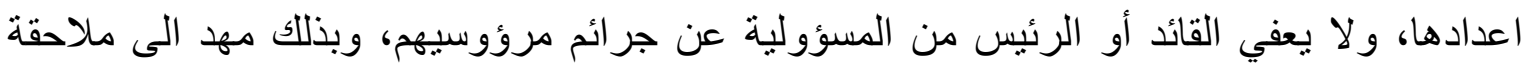

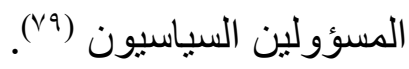

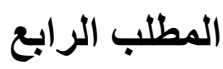 \\ مسؤولية القادة عن أعمال مرؤوسيهم}

\section{Responsibility of Commanders and Other Superiors}

ان مسؤولية القادة عن أعمال مرؤوسيهم فرضها القانون الجنائي الدولي وحدد المسؤولية الجنائية على

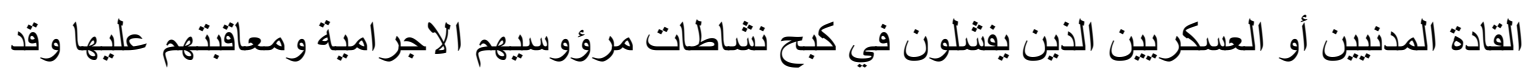

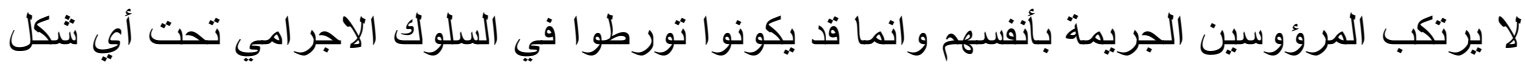

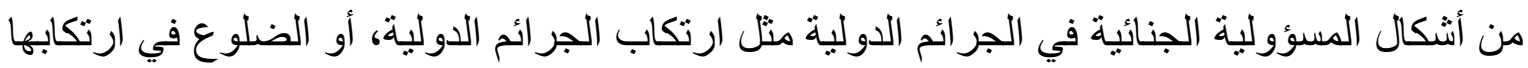
او التورط في مشروع اجر امي مشترك وغير ها، ويشترط ايضا ضرورة لجان علم القائد بالجر ائم التي

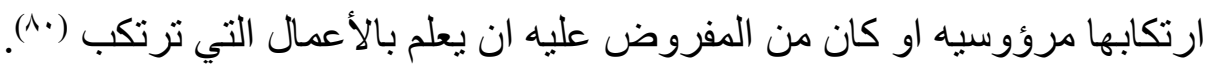

وقد ميز النظام الأساسي للمحكمة الجنائية الدولية في المادة (Y^) بين القائدة العسكريين وغير

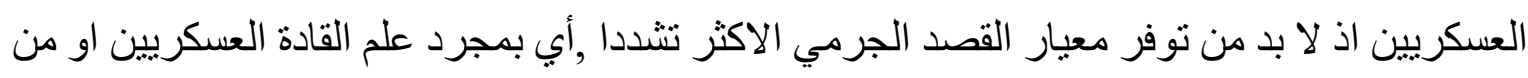

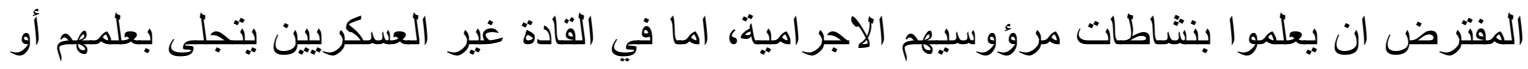
التعمد في اغفال معلومات تشير الى ارتكاب او التحضير مرؤوسيهم لجريمة ضمن اختصاص المحكمة ويجب ان يكون هناك تقصير من قبل القائد عن ممارسة سبطرته بالثكل المطلوب لمرؤوسيه، بمعنى ان يكون امتناع القائد عن القيام بفعل زاد خطر ارتكاب الجريمة ('^). 
كما وان الامر بارتكاب جرائم دولية وهو نمط من المسؤولية الذي يكون للشخص الامر له النفوذ الذي قد يجبر جانبا اخر على ارتكاب جريمة نتيجة اتباعه لأوامر صاحب النفوذ عليه ولا يشترط توفر

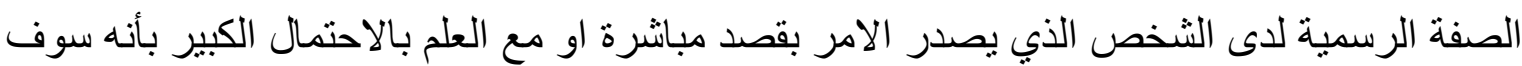
ترنكب جريمة تتفيذا للأمر ورغم ذللك و افق على هذه المخاطرة (r؟). وخلاصة ما تقام فان عناصر مسؤولية القادة عن أعمال مرؤوسيهم وفقا للنظام الاساسي للمحكمة الجنائية الدولية تتكون من العناصر التالية: أــ العلاقة التبعية بين القادة ومن يرتكب الجريمة او من كان على وشك ارتكابها. بـ علم القائد أو استنتاجه بتورط مرؤوسيه بارنكاب الجريمة. تــ تقصير القائد في منع ارتكاب مرؤوسيه الجر ائم او عدم معاقبتهم عليها. ثـ ثبوت تقصير القائد في فرض سيطرته على مرؤوسيا.

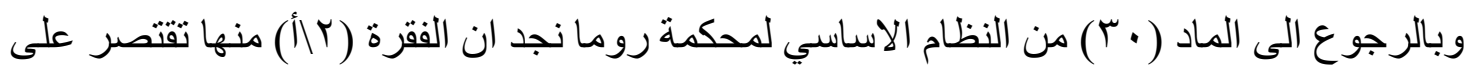
السلوك الايجابي فقط، وان حالات الامتتاع لا يغطيها النظام الاساسي، على قصد المادة أعلاه من توفر الار ادة و العلم، ويرى البعض ان " التعريفات الخاصة بمعظم الجر ائم المنصوص عليها في نظام روما الاساسي تتص صر احة على انها ترتكب بو اسطة الفعل فقط, ومع ذلك فإنها يمكن ان تفسر حيث تثمل الامتناع كذلك"، ويعد القرار الذي صدر من قبل الدائرة التمهيدية الاولى للمحكمة الجنائية الدولية في قضية (لو بانغا) دليلا على اخذ المحكمة بتجريم الاعمال التي ترتكب عن طريق سلوك سلبي (الامتتاع) عندما اثشارت المحكمة صر احة الى شمول السلوك الذكور في المادة (•r) الفعل أو الامتتاع عن فعل، وسواء عن طريق عمدا أو اهمالا, وان ما ذهبت الية المحكمة هو الصواب في تجريم الجرائم الدولية

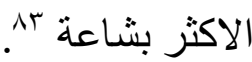

ويلاحظ ان الاهمال قد يؤدي الى اثارة المسؤولية الدولية الجنائية الفردية عندما يقوم قادة دولة ما بدعم مجمو عات مسلحة ارهابية، ماليا وعسكريا، دون ان يكون لهم قصد مشترك مع تلاك المجموعات المسلحة لارتكاب جر ائم دولية، ولكن ينبغي عليهم ان يتوقعو ا بشكل معقول ان تقديم اسلحة والتدريب و الدعم اللوجستي لهذه الجماعات قد يمكنها من ارتكاب جرائم ارهابية، بالاستناد الى الفقرة (؟) من المادة (Y^) و التي اثتترطت مستوى اعلى من الاهمال فيما يتعلق بالقادة المدنيين, ويعرف بالتهور أي لهاب "تجاهل الفاعل لخطر حدوث النتيجة عن وعي"، اما بالنسبة للقادة العسكريين فبالاستناد الى حكم المادة 
(־) من خلال النص " ما لم ينص على خلاف ذللك, أب وفق معيار الاهمال الجسيم ع^. ويتم من خلال

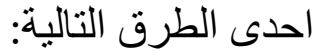

أــ احالة القضايا الى المحكمة الجنائية الدولية, ويتم بطلب من الدول الطرف في النظام الاساسي

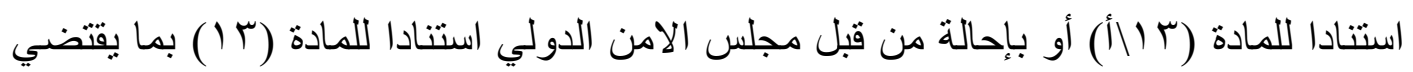

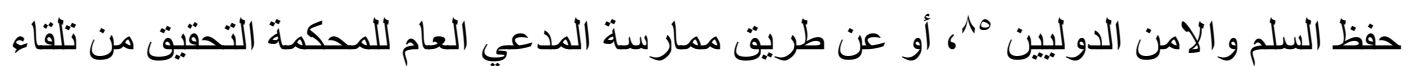
نفسه وفق المادة (10) - (10). ب- طلب تشكيل محكمة دولية مختلطة على غرار تشكل المحكمة الجنائية الخاصة بلبنان، وخصوصا مسألة تتظيم داعش الارهابي و الذي سوف يكثف عن حقائق تورط قادة ومسؤولين

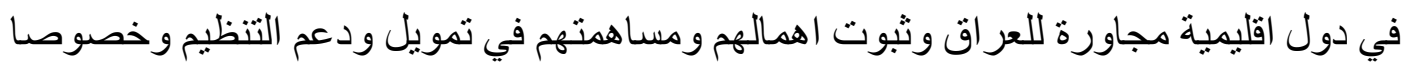

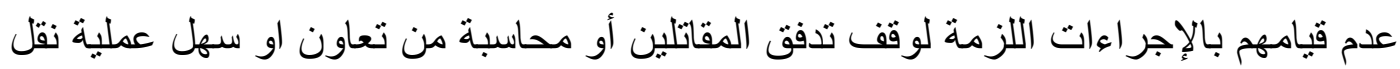
وبيع وتحويل الاموال الى التنظيم الار هابي وهو ما يندرج تحت مسؤولية المساهمة الجنائية و الاهمال الو اعي ومخالفة قرار ات مجلس الامن الدولي التي صدرت استنادا للفصل السابع. 


\section{الخاتمة}

\section{Conclusion}

وفي ختام بحثنا هذا تبين لنا وجود قو اعد دولية ذات صلة بالإر هاب، من خلال الاتفاقيات الدولية وقرار ات الجمعية العمومية للأمم المتحدة وقرار ات مجلس الأمن الدولي، والتي يمكن الاستتاد اليها في تحديد مسؤولية الدولة و الأفراد، عند مخالفتهم لها وان مخالفتها يعتبر ارتكاب فعل غير مشروع دوليا ويستوجب المسؤولية الدولية. وان أغلب العمليات الإر هابية ترتكب من خلال الإرهاب العابر للوطنية، و غالبا ما يتم تنفيذه من قبل أجانب، وخاصة الإرهاب المدعوم من قبل الدولة كوسيلة منها في إخفاء

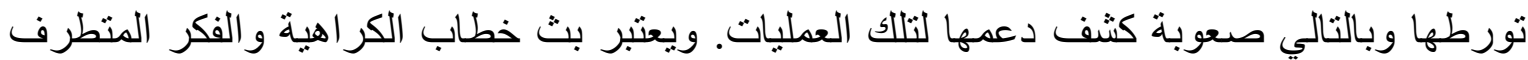
و التحريض على ارتكاب الأعمال الإرهابية من أهم الوسائل التي تستخدمها المجموعات أو المنظمات الإرهابية لكسب أكبر عدد ممكن من مناصريهم، وحصولهم على دعم وتمويل أسر ع من خلال التأثثر على المتعاطفين أو المغرور بهم جراء التحريض ونشر الفكر المتطرف. وتتحمل الدولة المسؤولية الدولية عن أفعال سلطتها التتفيذية وعن رعاياها عند ارتكاب عملا غير مشروع دوليا ينسب إليها، وبالقدر الأكبر عند دعمها للعمليات الإرهابية، وتثبت المسؤولية الدولية عن دعم الإرهاب في حالة

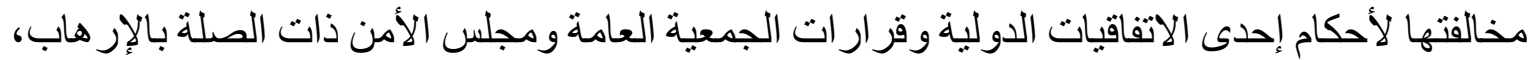
ويعتبر عملا يهدد الأمن و السلم الدوليين. ان مسؤولية الدولة تقوم من خلال اللجوء الى القضاء الوطني في بعض الدول أو القضاء الدولي أو باللجوء إلى محكمة العدل الدولية. ويتحمل الأفراد الدسؤولية

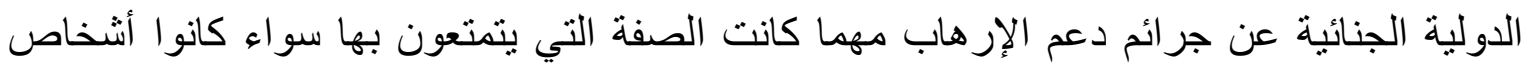
عاديين أو رؤساء دول أو موظفي دولة، ويمكن مسألتهم من خلال القضاء الوطني أو القضاء الدولي. وبالرغم من عدم ذكر الجرائم الإرهابية في النظام الأساسي للدحكمة الجنائية الدولية، إلا أنه يمكن محاكمة الجماعات الإرهابية أمام المحكمة الجنائية الدولية عند ارتكابهم جر ائم دولية ضمن الجرائم

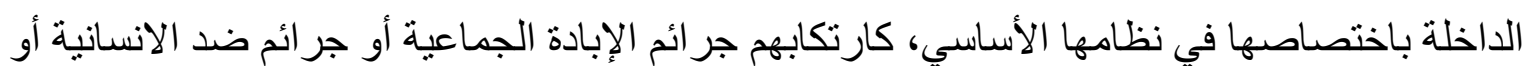
جر ائم حرب، ومحاكمة قادة ومسؤولي الدول الداعمة للإرهاب تبعا لهم على أساس أحكام الدساهمة الجنائية في ارتكاب جر ائم دولية تدخل في نطاق اختصاص الحكمة الجنائية الدولية. 


\section{الههو(مش}

\section{Margins}

' يوسف كوران. جريمة الار هاب و المسؤولية المترتبة عنها في القانون الجنائي الداخلي و الدولي، السليمانية: مركز

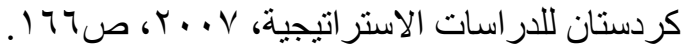

ץ محمد الراجي. المسؤولية الجنائية الدولية ودور ها في حماية حقوق الإنسان، مجلة المستقبل العربي، العدد بس؟,

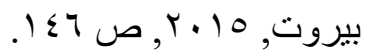

r عبد الجبار رشيد الجميلي. عولمة القانون الجنائي الدولي وأثرها في حفظ الأمن و السلم الدوليين، طا، لبنان:

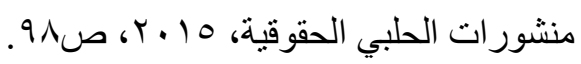

" شريف عتلم. المحكمة الجنائية الدولية، الموائمات الدستورية والتشريعية "مشروع قانون نموذج"، طس، اللجنة

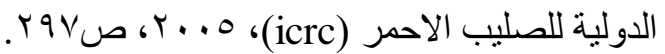
• حسين مال الله. مسؤولية القادة والرؤساء والدفع بإطاعة الاو امر العليا في القانون الدولي الانساني: دليل للتطبيق على الصعيد الوطني"، طع ، القاهرة: بعثة اللجنة الدولية للصليب الاحمر بالقاهرة، ( • ؟، ص. • و وما بعدها. " فتوح عبد الله الثاذلي. القانون الدولي الجنائي "أوليات القانون الدولي الجنائي ـ النظرية العامة للجريمة الدولية

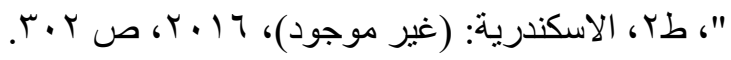

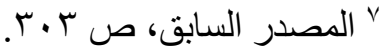

^ فاروق محمد صادق الاعرجي. المحكمة الجنائية الدولية" نثأتها وطبيعتها ونظامها الاساسي" در اسة في القانون

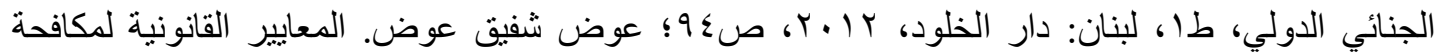

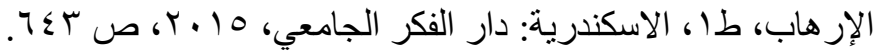
9 عقيل عزيز عودة. الار هاب ومكافحته في القانون الجزائي العر اقي، بحث منشور في مجلة القانون للدراسات

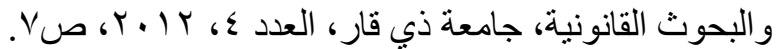

${ }^{10}$ Indian terror attacks, NY times (nov.26,2008)

http: www.ntimes. Com-2008-11-27-worid-asia-27 Mumbai. Html? Pagewanted=all [http: perma.cc-pgx5-n9a9].

${ }^{11}$ Ibid rا أحمد عبيس نعمة. ومسلم صالح المهنا. دراسة قانونية تحليلية حيال دور المحامي في ضوء الدولية الانسانية،

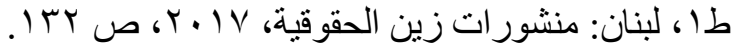

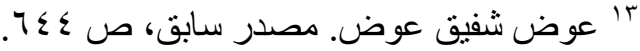

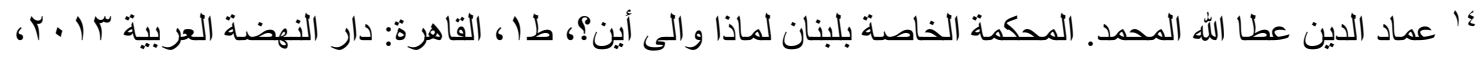
ص..

10 أحمد سيف الدين. الاتجاهات الحديثة للقضاء الدولي الجزائي، طا، لبنان: منشورات الحلبي الحقوقية، ص 


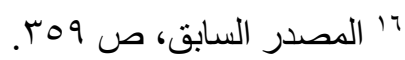

Vا ينظر الفقرة (ON)، من مجموعة الاجنهادات الصادرة عن المحكمة الجنائية الدولية في لبنان، رقم القضية:

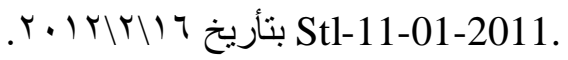

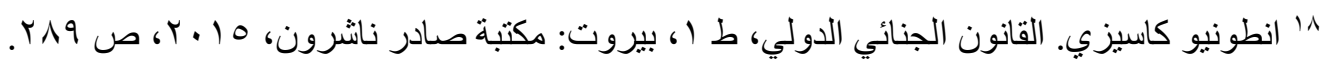

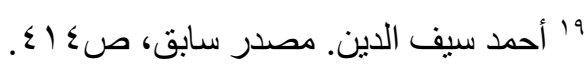

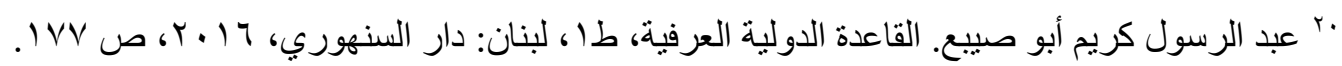
"r زياد عبد الوهاب النعيمي. سلطة الامم المتحدة في تنكيل محكمة وفق الفصل السابع من ميثاق الامم المتحدة:

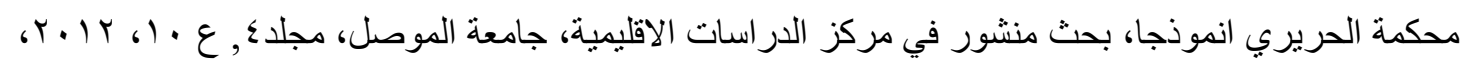

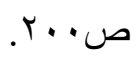
r محمد جبار جدوع. اختصاص المحكمة الجنائية الدولية في محاسبة مرتكبي جريمة اسبايكر، بيروت: دار

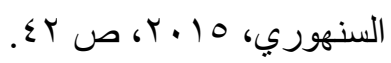

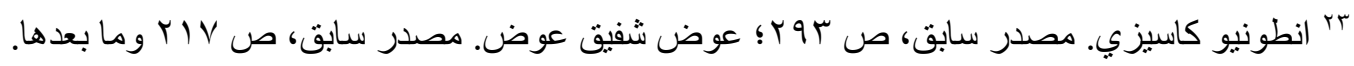

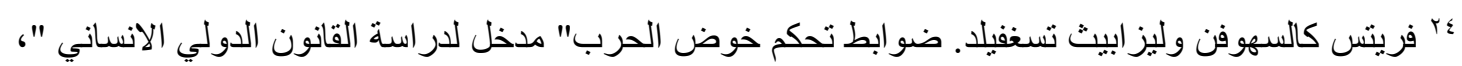

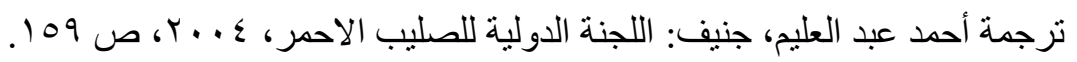

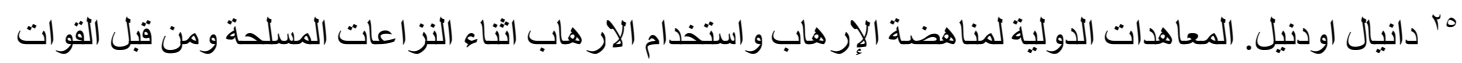

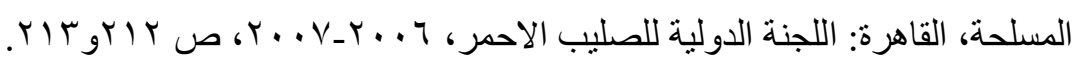

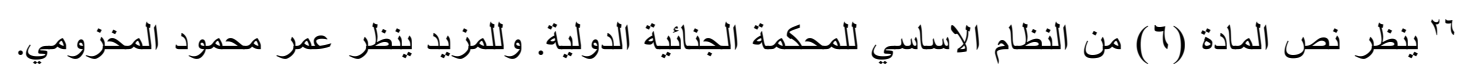

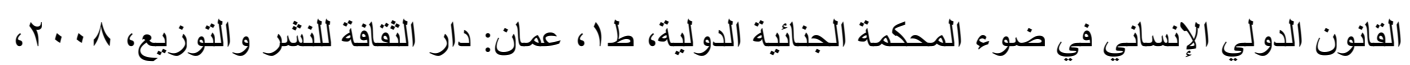

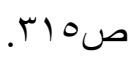

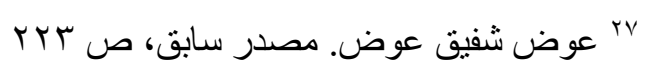

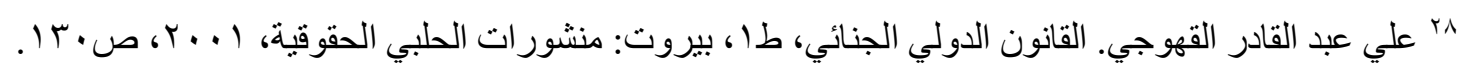
9r محمد جدوع العبدلي. اختصاص المحكمة الجنائية الدولية في محاسبة مرتكبي جريمة سبايكر، مصدر سابق، صטי.

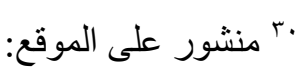
. أخر زيارة WwW.alsumaria.tv "ب محمود شريف بسيوني. المحكمة الجنائية الدولية "مدخل لدر اسة أحكام واليات الإنفاذ الوطني للنظام الأساسي"،

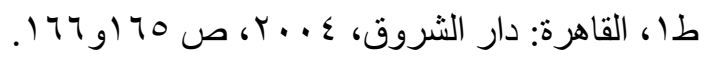

$$
\begin{aligned}
& \text { r" انطونيو كاسيزي. مصدر سابق، ص . . r. }
\end{aligned}
$$

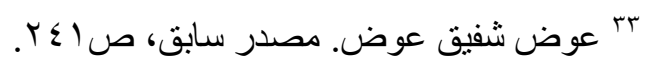

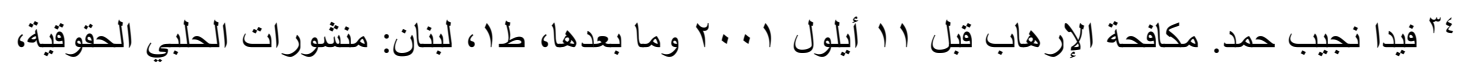

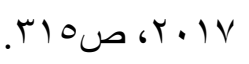

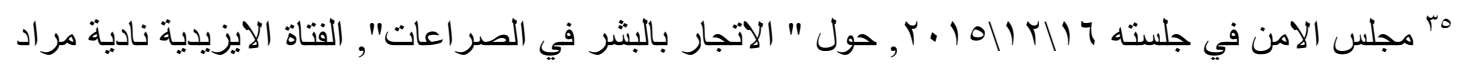
تروي تفاصيل اختطافها من قبل تتظيم داعش أمام مجلس الامن. متاح على الموقع: 
http; اخ زيارة

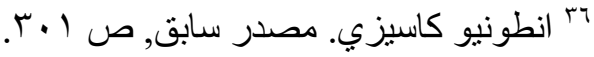

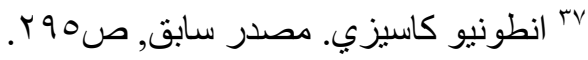

^ب عبد الفتاح مر اد. موسو عة شرح الإرهاب، الاسكندرية: شركة البهاء للبرمجيات والنشر الالكتروني، بدون سنة

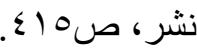

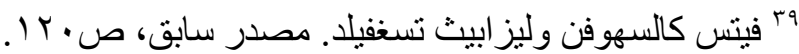
•" عوض شفيق عوض. مصدر سابق، ص Y74.

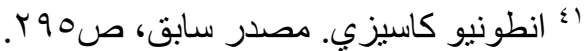

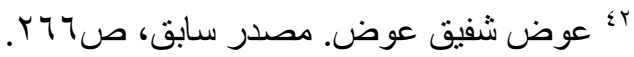
rاء ضيف الله بن شبيب الجبلي. المساهمة التبعية في ارتكاب الجريمة الإر هابية وعقوبتها "دراسة تأصيلية تطبيقية

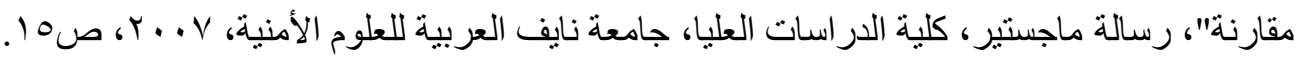

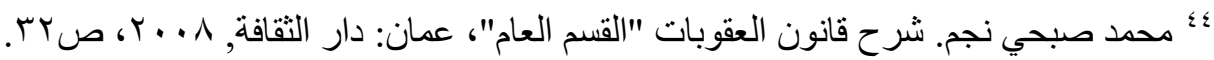
ه؛ علي حسين الخلف. الوسيط في شرح قانون العقوبات "المبادئ العامة"، طا، ج) ، بغداد: مطبعة الزهراء، .00rg0010، ص1970

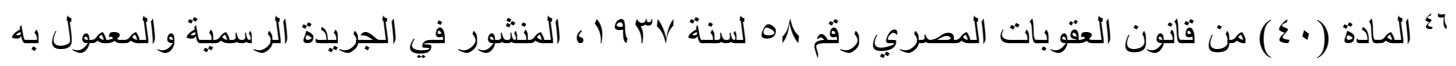

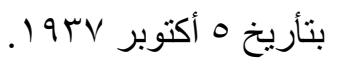

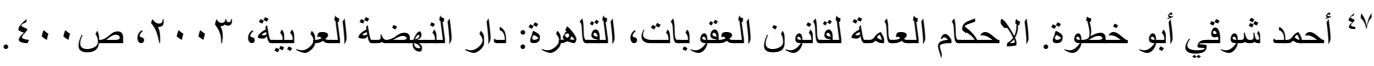

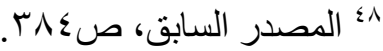
9؛ سليمان عبد المنعم. النظرية العامة لقانون العقوبات "دراسة مقارنة"، بيروت: منشورات الحلبي الحقوقية،

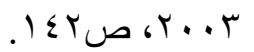

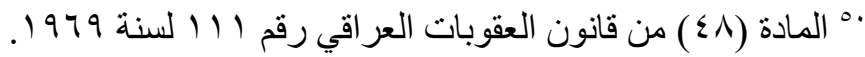

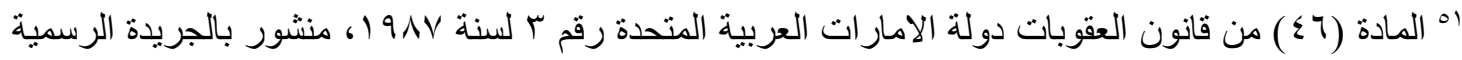

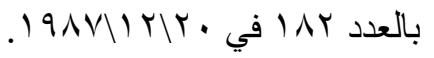

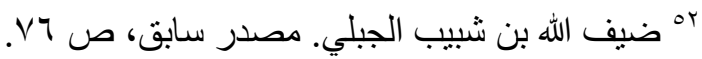

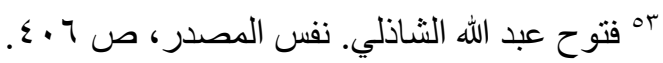

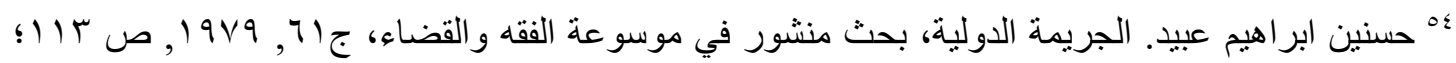

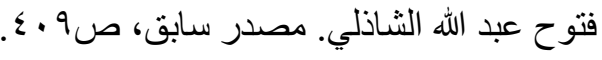

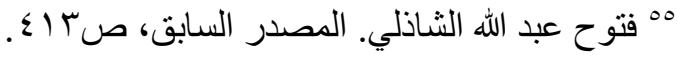

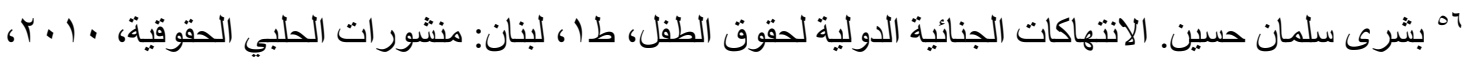

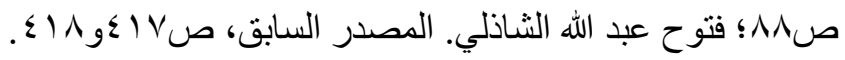
ro ابتهال فاضل عبد. المسؤولية الجنائية الفردية عن الإهمال في ضوء القانون الجنائي الدولي، رسالة ماجستير،

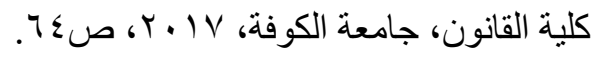


1ه جمال ابراهيم الحيدري، الوافي في شرح أحكام القسم العام من قانون العقوبات، بغداد: مكتبة السنهوري،

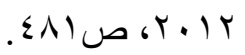

9ه محمد سعيد نمور. دراسات فقهية في القانون الجنائي "الفاعل المعنوي", طا، عمان: دار الثقافة، ؟ . . ؟، صטיד • ^ اسامة حسين محي الدين. جرائم الإر هاب المعاصر على المستوى الدولي و المحلي، الاسكندرية: المكتب العربي

" ماركو ساسولي وانطوان بوفييه. " كيف يوفر القانون الحماية في الحرب ؟؛ مختارات من القضايا الخاصة

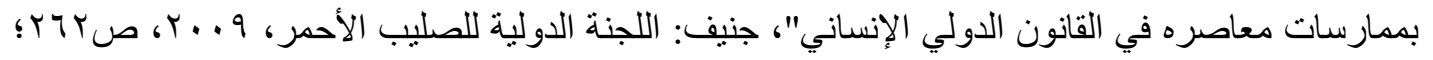
علي حسين خلف وسلطان عبد القادر الثناوي. المبادئ العامة في قانون العقوبات، الكويت: مطابع الرسالة، r)

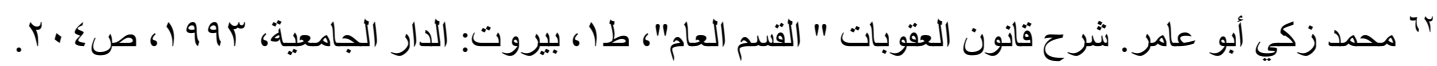

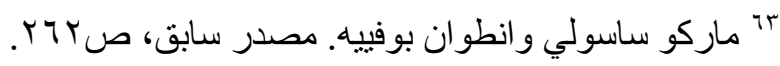
ء7 ابتهال فاضل عبد. مصدر سابق، صآ 7. 10 انطونيو كاسيزي. مصدر سابق، ص ا اب وما بعدها.

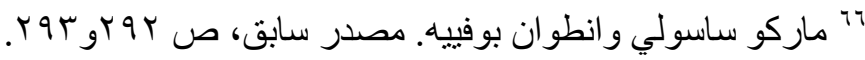
VT انطونيو كاسيزي. مصدر سابق، ص اVV

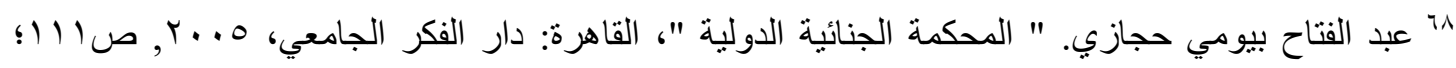
وانطونيو كاسيزي. مصدر سابق، ص سبس. 9 19 ابتهال فاضل عباس. المسؤولية الجنائية الفردية النانشئة عن الإهمال في ضوء القانون الجنائي الدولي، رسالة

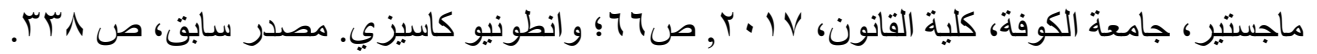

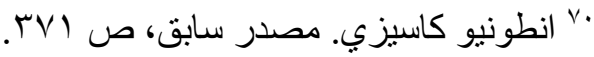

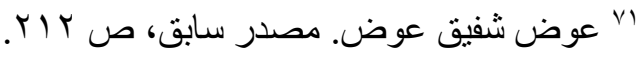

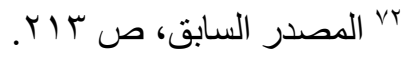

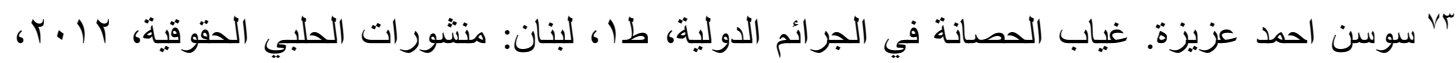
صט0 ءع احمد ابو الوفا. المسؤولية الدولية للدول واضعة الألغام في الار اضي المصرية، القاهرة: دار النهضة العربية، .$\Sigma 990$ ص.

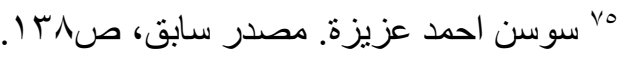
بو اياد خلف محمد، حسان صادق حاجم. المسؤولية الجنائية الدولية لرؤساء الدول، بحث منشور في المجلة السياسية

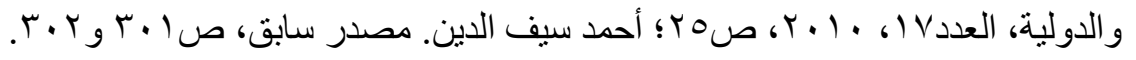
NV عمر محمود المخزومي. القانون الدولي الانساني " في ضوء المحكمة الجنائية الدولية، مصدر سابق، صسبr. NA محمد حسن القاسمي. إنشاء المحكمة الجنائية الدولية الدائمة "هل هي خطوة حقيقية لتطوير النظام القانوني

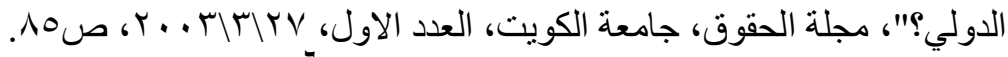


مجلة العلوم القانونية/ كلية القانون - جامعة بغداد / العدد الخاص لبحوث مؤتمر فرع القانون الجنائي المنعق تحت

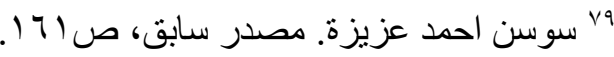
•^ زياد عيتاني. المحكمة الجنائية الدولية وتطور القانون الدولي الجنائي، طا ، بيروت: منشورات الحلبي الحقوقية،

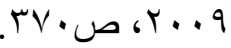
ای عبد الامير عبد الحسن ابراهيم. طبيعة مسؤولية الفرد الجنائية عن ارتكاب الجرائم الدولية، بحث منشور في

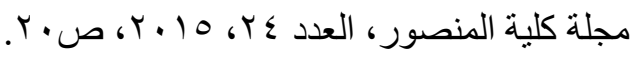

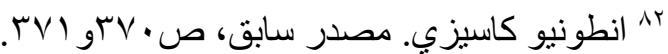
rی سوسن تمر خان بكة. الجر ائم الإنسانية في ضو ء أحكام النظام الأساسي للمحكمة الجنائية الدولية، طا (، بيروت:

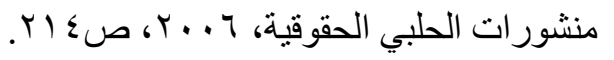
ع^ محمد سمير ناجي. المحكمة الجنائية الدولية "المبادئ التي يقوم عليها نظامها الاساسي", مقال منشور في المجلة

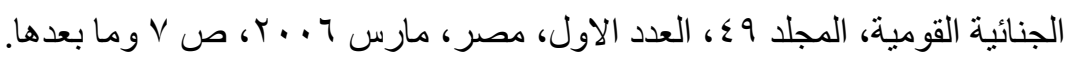
101 عصام عبد الفتاح مطر. القضاء الجنائي الدولي، الاسكندرية: دار الجامعة الجديدة، ^ . . r، ص اسب وما بعدها. 
المصادر

\section{References}

أولا:الكتب

I

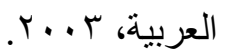

أحمد سيف الدين. الاتجاهات الحديثة للقضاء الدولي الجزائي، طا ، لبنان: منشورات الحلبي الحقوقية.

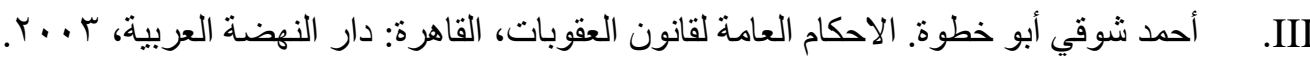

.IV

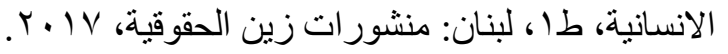

اسامة حسين محي الدين. جر ائم الإر هاب المعاصر على المستوى الدولي والمحلي، الاسكندرية: المكتب

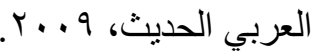

. II

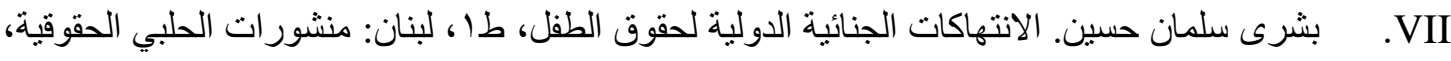

$r \cdot 1 \cdot$

جمال ابر اهيم الحيدري، الو افي في شرح أحكام القسم العام من قانون العقوبات، بغداد: مكتبة السنهوري، .VIII

$r \cdot 1 r$

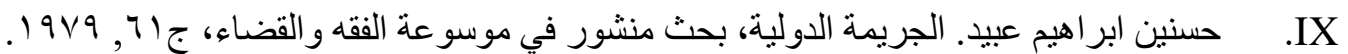

حسين مال الله. مسؤولية القادة و الرؤساء و الدفع بإطاعة الاوامر العليا في القانون الدولي الانساني: دليل

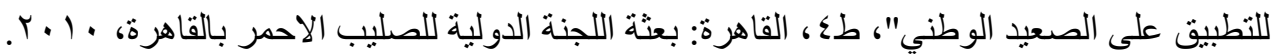
دانيال اودنيل. المعاهدات الدولية لمناهضة الإرهاب و استخدام الار هاب اثناء النزاعات المسلحة ومن قبل

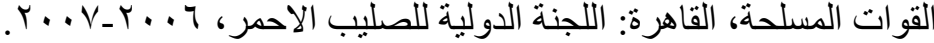

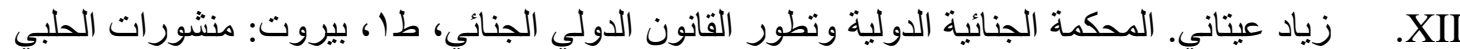

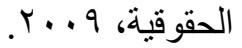

سليمان عبد المنعم. النظرية العامة لقانون العقوبات "در اسة مقارنة"، بيروت: منشور ات الحلبي الحقوقية،

r..r

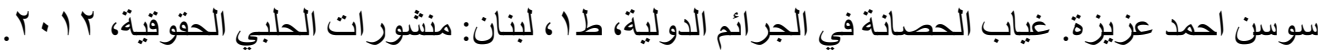

سوسن تمر خان بكة. الجرائم الإنسانية في ضوء أحكام النظام الأساسي للمحكمة الجنائية الدولية، طان،

. $\mathrm{XV}$

بيروت: منشور ات الحلبي الحقوقية، 7 . . ب.

شريف عتلم. المحكمة الجنائية الدولية، الموائمات الدستورية و التشريعية "مشروع قانون نموذج"، طس، 
عبد الجبار رشيد الجميلي. عولمة القانون الجنائي الدولي وأثرها في حفظ الأمن والسلم الدوليين، طا،

XVII

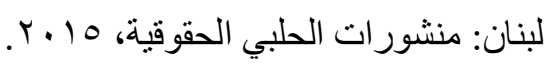

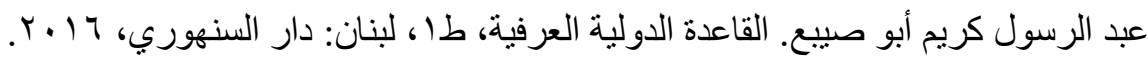

. XVIII

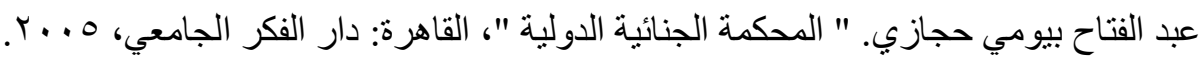

.XIX

عبد الفتاح مر اد. موسوعة شرح الإرهاب، الاسكندرية: شركة البهاء للبرمجيات والنشر الالكتروني،

. $\mathrm{XX}$

بدون سنة نشر.

عصام عبد الفتاح مطر ـ القضاء الجنائي الدولي، الاسكندرية: دار الجامعة الجديدة، م . . r.

.XXI

علي حسين الخلف. الوسيط في شرح قانون العقوبات "المبادئ العامة"، طا ، ج ج ، بغداد: مطبعة الزهر اء،

.XXII

.1970

علي حسين خلف وسلطان عبد القادر الثشاوي. المبادئ العامة في قانون العقوبات، الكويت: مطابع

.XXIII

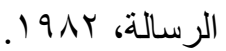

علي عبد القادر القهوجي. القانون الدولي الجنائي، طا ، بيروت: منشورات الحلبي الحقوقية، ا. .. بـ. عماد الدين عطا الله المحمد. المحكمة الخاصة بلبنان لماذا و الى أين؟، طا ، القاهرة: دار النهضة العربية

.XXIV

. $\mathrm{XXV}$

$r \cdot 1 r$

عمر محمود المخزومي. القانون الدولي الإنساني في ضوء المحكمة الجنائية الدولية، طا، عمان: دار

.$X X V I$

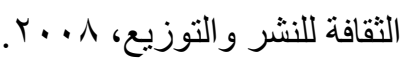

عوض شفيق عوض. المعايير القانونية لمكافحة الإر هاب، طا ، الاسكندرية: دار الفكر الجامعي، 10 • ب.

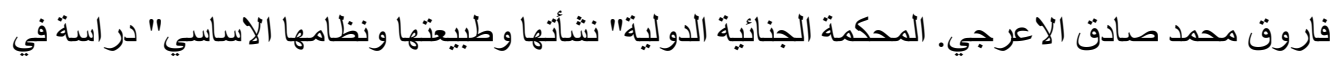

XXVII

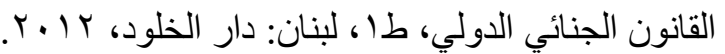

فتوح عبد الله الثاذلي. القانون الدولي الجنائي "أوليات القانون الدولي الجنائي ـ النظرية العامة للجريمة

.XXIX

$$
\text { الدولية "، طץ، الاسكندرية: (غير موجود)، } 17 \text { • ب. }
$$

فريتس كالسهوفن وليز ابيث تسغفيلا. ضو ابط تحكم خوض الحرب" مدخل لدر اسة القانون الدولي الانساني

. $\mathrm{XXX}$

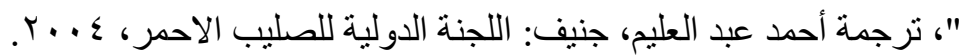

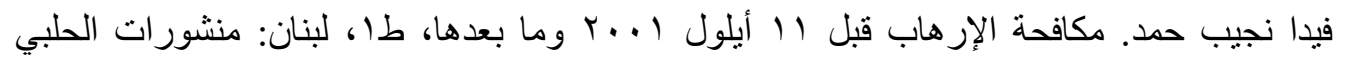

XXXI

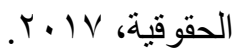

ماركو ساسولي و انطوان بوفييه. " كيف يوفر القانون الحماية في الحرب ؟؛ مختار ات من القضايا الخاصة

XXXII

بممارسات معاصره في القانون الدولي الإنساني"، جنيف: اللجنة الدولية للصليب الأحمر، 9 9. . . . . محمد الراجي. المسؤولية الجنائية الدولية ودور ها في حماية حقوق الإنسان، مجلة المستقبل العربي، العدد

XXXIII

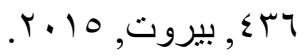

محمد جبار جدوع. اختصاص المحكمة الجنائية الدولية في محاسبة مرتكبي جريمة اسبايكر، بيروت:

.XXXIV

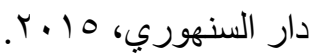

محمد زكي أبو عامر. شرح قانون العقوبات " القسم العام"، طا، بيروت: الدار الجامعية، ب99 19.

محمد سعيد نمور ـ دراسات فقهية في القانون الجنائي "الفاعل المعنوي", طا، عمان: دار الثقافة، ـ . . ب. 


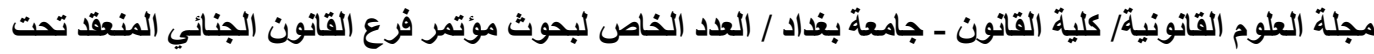

$$
\text { محمد صبحي نجم. شرح قانون العقوبات "القسم العام"، عمان: دار الثقافة, ^ ـ. †. }
$$

محمود شريف بسيوني. المحكمة الجنائية الدولية "مدخل لدراسة أحكام و اليات الإنفاذ الوطني للنظام

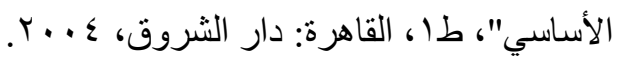

يوسف كوران. جريمة الارهاب والمسؤولية المترتبة عنها في القانون الجنائي الداخلي والدولي،

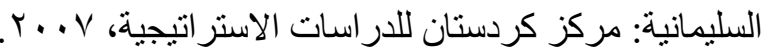

$$
\text { ثانيا: الرسائل والأطاريح }
$$

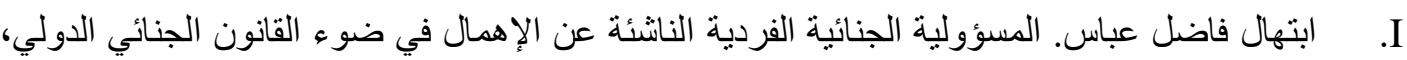

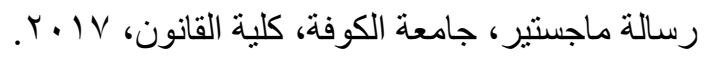

ضيف الله بن شبيب الجبلي. المساهمة التبعية في ارتكاب الجريمة الإر هابية وعقوبتها "دراسة تأصيلية $\quad$.II

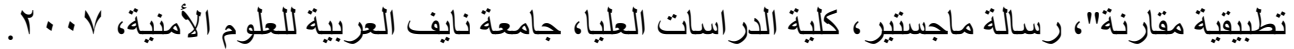

$$
\text { ثالثا: البحوث }
$$

II $\quad$. I

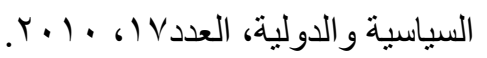

II المتحدة: محكمة الحريري انموذجا، بحث منشور في مركز الدر اسات الاقليمية، جامعة الموصل، مجلد ؛

$$
\left..+1 r_{6}\right) \cdot \varepsilon
$$

عبد الامير عبد الحسن ابر اهيم. طبيعة مسؤولية الفرد الجنائية عن ارتكاب الجرائم الدولية، بحث منشور

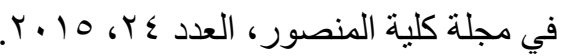

عقيل عزيز عودة. الارهاب ومكافحته في القانون الجزائي العراقي، بحث منشور في مجلة القانون

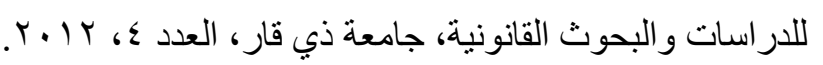

محمد حسن القاسمي. إنشاء المحكمة الجنائية الدولية الدائمة "هل هي خطوة حقيقية لتهولة لتطوير النظام القانوني

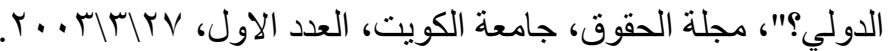
محمد سمير ناجي. المحكمة الجنائية الدولية "المبادئ التي يقوم عليها نظامها الاساسي", مقال منشور في

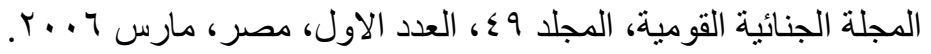


مجلة العلوم القانونية/ كلية القانون - جامعة بغداد / العدد الخاص لبحوث مؤتمر فرع القانون الجنائي المنعقد تحت

$$
\begin{aligned}
& \text { رابعا: الوثائق }
\end{aligned}
$$

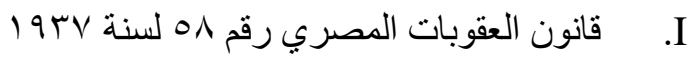

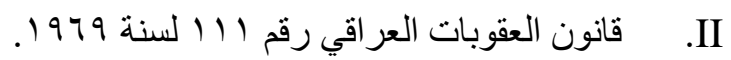

$$
\begin{aligned}
& \text { I 9AV قانون العقوبات دولة الامار ات العربية المتحدة رقم ب لسنة }
\end{aligned}
$$

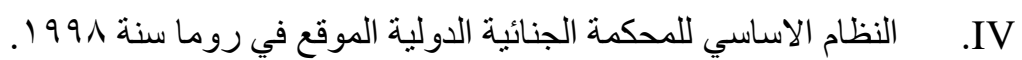

Stl-11-01-2011 . . V

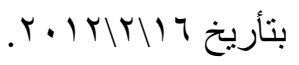

خامسا:المواقع الاككترونية

I. Indian terror attacks, NY times (nov.26,2008) http: www.ntimes. Com-200811-27-worid-asia-27 Mumbai. Html? Pagewanted=all [http: perma.cc-pgx5n9a9]. 